\title{
Connected and Autonomous Vehicles and Infrastructures: A Literature Review
}

\author{
Md. Masud Rana ${ }^{1,2}$ (D) $\cdot$ Kamal Hossain ${ }^{3}$
}

Received: 13 June 2021 / Revised: 26 October 2021 / Accepted: 4 November 2021 / Published online: 24 November 2021

(c) The Author(s), under exclusive licence to Chinese Society of Pavement Engineering 2021

\begin{abstract}
The continuous integration of advanced driver-assist systems (ADAS) into connected and autonomous vehicles (CAV) is accelerating the transition of human-driven vehicles to a fully driverless option. The most available ADASs in current running vehicles with their functions, level of autonomy, and present scenario of CAV deployment are critically reviewed and summarized in this paper. The expected advantages with the probable and observed uncertainties of the CAV deployment are also presented. The technological accomplishments (advanced digital infrastructures along with other technologies) are incorporating rapid improvement in vehicle automation. This paper reviews the engagement of technologies in the functioning of automated vehicles and their implementation challenges. Physical infrastructures facilitate the features of automation and connectivity in moving on the roads. Various roadside infrastructures with the issues in assisting the CAV for path tracking are summarized in this paper. The reduction of lane width due to lane-keeping ADAS and replacement of human drivers (i.e., eye) by machine impacts the various geometric elements of highways. The reduced lane width and truck platooning from the integration of cooperative adaptive cruise control affect the structural performance of the pavements significantly. This paper addresses the effects of connected and automated driving on geometric elements and the structural performance of highways. In addition, various techniques to minimize the additional distresses of connected and automated driving are also explained in this paper.
\end{abstract}

Keywords Connected and autonomous vehicles · Technological accomplishment $\cdot$ Physical infrastructures · Geometric elements · Pavement performance

\section{Introduction}

The commercial application of automation technology in passenger and freight transport is growing rapidly due to tremendous development in Intelligent Transportation Systems (ITS). The deployment of ITS in connected vehicle

Md. Masud Rana

mrana@mun.ca

Kamal Hossain

kamal.hossain@carleton.ca

1 Department of Civil Engineering, Rajshahi University of Engineering and Technology, Rajshahi 6204, Bangladesh

2 Department of Civil Engineering, Memorial University of Newfoundland, St. John's, NL A1B 3X5, Canada

3 Department of Civil and Environmental Engineering, Advanced Road and Transportation Engineering Lab (ARTEL), Carleton University, Memorial University of Newfoundland, Ottawa, ON K1S 5B6, Canada
(CV) and autonomous vehicle (AV) will bring revolutionary changes in transportation mobility in the near future. CVs use communication technologies to establish connections with autonomous and non-autonomous vehicles, roadside infrastructures, and other road participants to share the driving information (Fig. 1b). CVs help human or autonomous drivers to make a better choice by supplying information collected by wireless technologies [1]. AV, also known as driverless vehicles, can move from one place to another using sensors and communication module (shown in Fig. 1a) without any human intervention. AVs conduct driving tasks relying on various sensors and systems and reduce human assistance based on autonomy level (presented in the next section). There is a belief among transportation stakeholders that $\mathrm{CV}$ is the enabler of the $\mathrm{AV}$ [2], and CV has a significant influence on the AV [3]. Connected and autonomous vehicle (CAV) incorporates both $\mathrm{AV}$ and $\mathrm{CV}$ technology, and this combination has more benefits than separated one. The features of automation and connectivity are in the development 


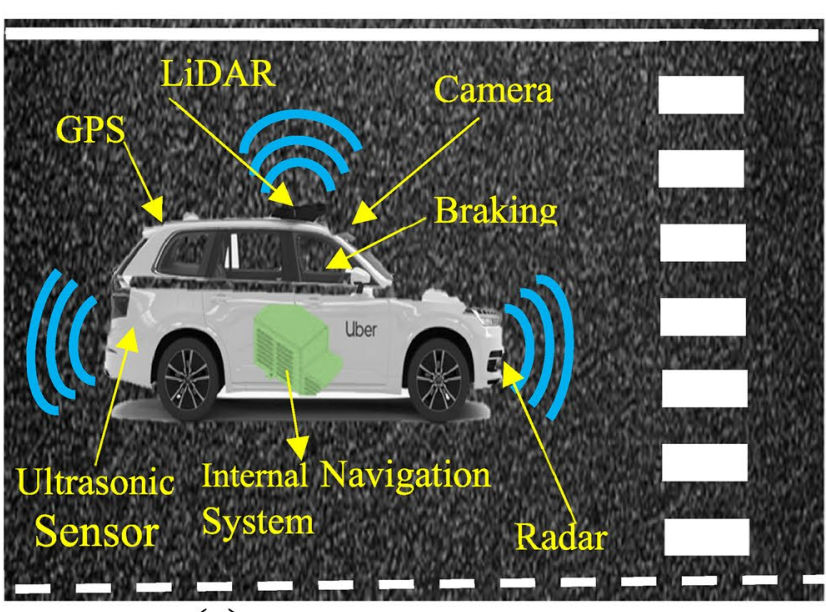

(a) Autonomous Vehicles

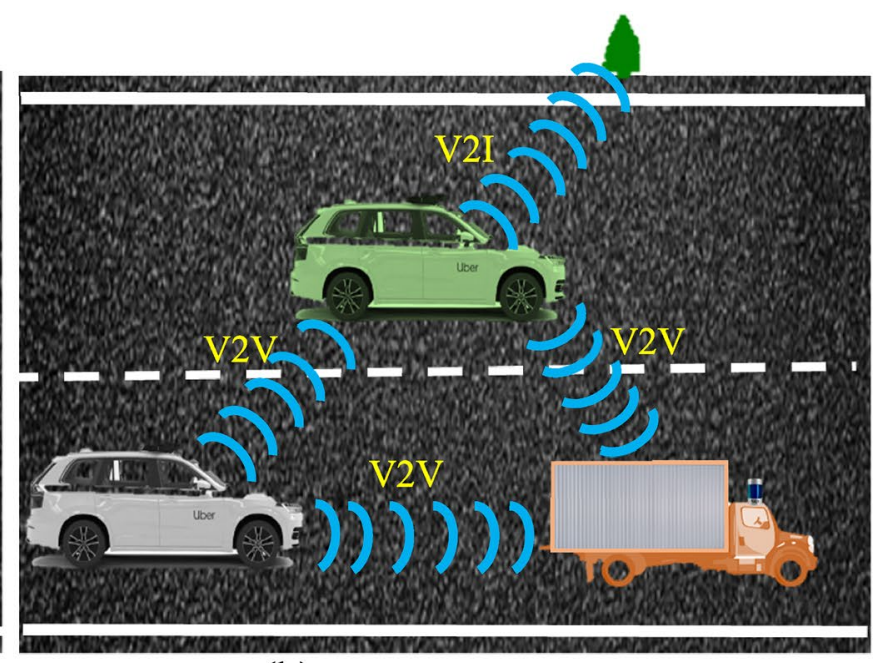

(b) Connected Vehicles

Fig. 1 a Autonomous and $\mathbf{b}$ connected vehicles

stage with key infrastructural and technological challenges. The existence of significant overlapping between AVs and CVs creates difficulties in selecting specific infrastructure requirements for each technology [4].

This paper aims to provide a brief overview of features and control systems of CAVs from a highway engineering perspective, the potential benefits and uncertainties related to CAV implementation. The technological evolution for $\mathrm{CAV}$ and the effects of CAV on pavement infrastructures are reviewed, and recommendations for future studies are presented. In Sect. 1, a brief overview of $\mathrm{AV}, \mathrm{CV}$ and $\mathrm{CAV}$ is introduced. Advancement in vehicle automation in the next section highlights the different driver-assist systems deployed in current vehicles, defines autonomy level with the progressive application of driver-assist systems on onroad vehicles and presents the scenario of CAV features in actual use and a pilot program of more advanced systems in ground vehicles. Section 3, named as effects of CAVs on transportation performance, describes the observed and probable advantages and uncertainties of CAV deployment. Section 4 focuses on necessary technologies in use and their critical challenges for CAV. Elements and requirements of physical infrastructures, emphasizing geometric elements and structural performance of highways, is broadly discussed in Sect. 5. In Sect. 5.1, the effects of CAV on geometric features (dimensions, layout) of the highway is discussed. The effects of CAV on the structural performance of asphalt pavement are illustrated in Sect. 5.2. This subsection describes the difference between human-driven and AVs, deliberates the significance of wheel wander in analyzing pavement distresses, describes the asphalt pavement distresses due to the movement of CAV, especially truck traffic, and reports about various techniques to minimize the asphalt pavement distresses. The issues of road infrastructures associated with AV movement and the potential research gaps from the review is presented in Sects. 6 and 7 , respectively. Concluding remarks draw several conclusions about the features of automation and connectivity, the infrastructures for CAV and challenges, the effects of CAV on geometric elements and structural components.

\section{Advancement in Vehicle Automation}

Over the last decades, progressive technological development has brought human-driven vehicles to the pilot program stage of fully AVs. The active and passive safety systems in modern vehicles initiated advancements in automation. The protection of human drivers and passengers is ensured with the provision of protocols like airbags and seat belts in passive safety systems. Active safety systems continuously monitor the driving environment and get engaged in controlling vehicles to reduce accidents and severity. This system includes advanced driver-assist systems (ADAS) to perform various functions.

\subsection{Advanced Driver-Assist Systems}

ADAS is an integrated part of ITS and assists the human driver in driving functions [5]. The level of automation is also characterized based on the relief of human tasks by ADAS. Different ADASs are currently integrated into human-driven vehicles [6]. The analysis found that the vast majority of new vehicles in the USA in 2018 would consist of at least one ADAS function [7]. The common ADAS 
technologies integrated into current vehicles [8] and their functions [7] are presented in Table 1.

ADASs are built-in functions in a large number of new vehicles and are in the development stage. These ADASs, introduced in various vehicles for increasing the comfort and safety of road users, are observed to face challenges. Lengyel et al. [6] simulated critical traffic scenarios based on driving experience with ADAS systems and examined the conflicts of speed assist, ACC and LKS with traffic infrastructures. The rule-following automated vehicles at reduced speed near the speed limit sign clashed with following humandriven vehicle, moving at the same speed. The detection of lane-changing vehicles in front as overtaking by automated vehicles created a hazardous condition. ACC and LKS conflicted with the arising situation. The inability of ACC and emergency braking systems caused the automated vehicles to fall into the accident. The improper working of the perception system of ADASs to simulate the actual situation is the reason for collisions. The appropriate use of ADASs by human drivers is essential to be beneficial in increasing safety. Prior knowledge of ADASs is necessary for using these systems in the vehicle and influences the adaptation speed [9]. Naturalistic driving data exhibited that human drivers with integrated ADASs looked away longer than conventional drivers [10].

\subsection{Level of Autonomy}

The ultimate goal of ADAS is to transform vehicles from human-driven to fully autonomous conditions. Transportation sectors have already entered into a new era of automation technology by the successful transformation of ADAS into fully automated driving systems (ADS). Automation in driving requires the execution of dynamic driving functions related to operational activities and tactical strategies. The steering, braking, accelerating, and monitoring are part of operational activities, and tactical strategy comprises different decisions about changing lanes and avoiding traffic congestions and construction zones. Society of Automotive Engineers (SAE), a global platform comprising scientists, engineers, and practitioners, classify passenger and freight transport automation into six levels [11]. These autonomy levels have been adopted by the United States Department of Transportation (USDOT) and the United Nations [12]. The National Highway Traffic Safety Administration (NHTSA) and German Federal Highway Research Institute (BASt) also defined the automation level [13, 14]. The fundamental elements of SAE [11], NHTSA [13] and BASt [14] autonomy are almost similar. The driving automation level with their corresponding human and autonomous functions is presented in Table 2.

The addition of cooperative adaptive cruise control (CACC) features with ADS has brought a new dimension to driverless vehicles, leading to the formation of traffic platooning. This connectivity (V2X technology) will allow AVs to communicate with everything (i.e., vehicles, infrastructures, network). This communication will facilitate the automated vehicles to transform into CAV. The introduction of V2X would reduce road accidents, increase traffic capacity, decrease negative environmental impacts, etc. [15].

Informational ADAS, the facilitator of Level 0 autonomy, senses the surroundings of the vehicle using various sensors. Microcontrollers and Electric Control Unit (ECU) placing in the vehicles, process the individual sensor data and warn the human driver about the obstacle. Informational ADAS has no control over driving functions. For Level $1 \mathrm{AVs}$, microcontrollers process the data of multiple sensors and map the all-around environment of the vehicle. ECU performs the safest action like steering and braking by the accurate interpretation of the scenario. ACC, LKS, and collision avoidance are the considerable Level 1 ADAS. In Level 2, advanced algorithms and artificial intelligence process the information received by various sensors. These systems use the processed data to perform different complex tasks like
Table 1 Different ADASs and their functions

\begin{tabular}{ll}
\hline ADAS & Functions \\
\hline Adaptive cruise control (ACC) & Accelerates or stops the vehicle along with many other functions \\
Back-up cameras/sensors & Assists in parking and observe the backside \\
Adaptive headlights & Make the headlight adjustment to notice at bends and corners in hill \\
Lane departure warning (LDW) & Warns the driver at the moment of leaving the lane \\
Lane centering assist (LCA) & Keeps the vehicles in the center of lane \\
Lane keeping system (LKS) & Confines the vehicles in the lane width \\
Automatic parking & Parks the cars automatically without any assistance \\
Blind spot monitoring & Alerts the drivers about objects in the blind spot \\
Emergency braking & Applies brakes to avoid the collision \\
Pedestrian detection & Differentiates between the pedestrians and objects \\
Drowsy driver detect & Prevents accidents by sleeping drivers \\
Night vision & Sees clearly at night or adverse weather \\
\hline
\end{tabular}


Table 2 Driving automation level

\begin{tabular}{|c|c|c|c|c|c|c|}
\hline \multirow[t]{2}{*}{ SAE level } & \multirow[t]{2}{*}{ Level name } & \multirow[t]{2}{*}{ Driving system } & \multicolumn{2}{|l|}{ Functions } & \multirow[t]{2}{*}{ BASt level } & \multirow[t]{2}{*}{ NHTSA level } \\
\hline & & & Human diver & Automated systems & & \\
\hline 0 & No Automation & ADAS & All driving tasks & $\begin{array}{l}\text { No technological } \\
\text { assistance }\end{array}$ & Drive only & No Automation \\
\hline 1 & Driver assistance & ADAS & $\begin{array}{l}\text { Monitor road environ- } \\
\text { ment and control } \\
\text { steering }\end{array}$ & $\begin{array}{l}\text { Assist in acceleration, } \\
\text { deceleration, and } \\
\text { braking }\end{array}$ & Assisted & $\begin{array}{l}\text { Function-specific } \\
\text { automation }\end{array}$ \\
\hline 2 & Partial automation & ADAS & $\begin{array}{l}\text { Monitor driving } \\
\text { environment and } \\
\text { can take control at } \\
\text { any time }\end{array}$ & $\begin{array}{l}\text { Handle steering, brak- } \\
\text { ing, and accelera- } \\
\text { tion }\end{array}$ & Partially automized & $\begin{array}{l}\text { Combined function } \\
\text { automation }\end{array}$ \\
\hline 3 & $\begin{array}{l}\text { Conditional automa- } \\
\text { tion }\end{array}$ & ADS & $\begin{array}{l}\text { Drive mandatorily } \\
\text { based on the request } \\
\text { by features }\end{array}$ & $\begin{array}{l}\text { Maintain steering, } \\
\text { braking, accelera- } \\
\text { tion, and navigation } \\
\text { control }\end{array}$ & Fully automized & $\begin{array}{l}\text { Limited self-driving } \\
\text { automation }\end{array}$ \\
\hline 4 & Highly automation & ADS & No responsibility & $\begin{array}{l}\text { Control operational } \\
\text { and tactical deci- } \\
\text { sions under good } \\
\text { weather conditions }\end{array}$ & Fully automized & $\begin{array}{l}\text { Full self-driving } \\
\text { automation }\end{array}$ \\
\hline 5 & Full automation & ADS & No driver required & $\begin{array}{l}\text { Handle all driving } \\
\text { tasks under all } \\
\text { weather conditions }\end{array}$ & & \\
\hline
\end{tabular}

automatic lane changes and automatic parking. The integration of lateral and longitudinal control in addition to steering and braking has transformed vehicle automation from Levels 2 to 3 [16]. AVs with Level 4 can perform the majority of driving functions. This level vehicles are limited for good weather conditions, and human has the option to take control. Fully AVs (Level 5) need to have many ADASs for handling any driving tasks.

Different organizations such as SAE [11], NHTSA [13], BASt [14] introduced the taxonomy of AVs in better understanding the progress of vehicle automation. The taxonomy of SAE is widely accepted, even has become standard in various countries for classifying the automation level of on-road vehicles. This vehicle classification system is not beyond the criticisms. Stayton and Stilgoe [17] mentioned four major limitations of SAE automation level as (1) the replacement of human tasks by the linear increment of level, (2) lacking of addressing the prospects of human-machine interaction, (3) the avoidance of discussions about the environment, infrastructure and social impacts, (4) the misuse due to labeling the small portion of the operation as level. Seppelt et al. [18] defined automation levels with an understandable set of drivers' responsibilities and compared them with the SAE automation level based on a field survey. The authors observed the better acceptability of new proposed automation levels. This sequential level indicates that the existence of hierarchy in technological perspectives is already present and progress is expected following the same direction. In reality, predictions of technological direction is uncertain for best engineers [19]. Although a lot of inconsistencies are existing in leveling AVs, the progress of CAV deployment is moving forward based on this automation level.

\subsection{Current State of CAV Deployment}

Informational ADAS (Level 0) is available in most of the modern vehicles. The new vehicles at the current time are equipped with at least one ADAS of Level 1. The Level 2 autonomous features are commercially available in various vehicles manufactured by Audi, Tesla, GM (Cadillac), Lexus, Porsche, Daimler, BMW and Volvo. Audi developed a traffic jam pilot with the ability to steering, braking and accelerating on the highway. The features of Audi are identical to Level 3 of the SAE classification. Legislation barriers stopped Audi from releasing this system in the market [16]. The experimental program of AVs (Level 4 and 5) is growing tremendously, and the feasibility of commercial deployment has been a reality from the technological point of view [20]. Waymo, the leading company of driverless vehicle development, has brought Level 4 self-driving taxis on public roads. This company conducted testing of the taxi in Arizona above 1 year and more than 10 million miles. The features of these driverless taxis can stop AVs from any occurrence of system failures. The French manufacturer, NAVYA, has started selling highly automated shuttles and cabs in different countries, including the US [21]. Beep and NAVYA partnered with the Jacksonville Transportation Authority, Florida, and a Chinese company, Baidu, successfully deployed logistic AVs to control the spreading of Covid-19. AVs were used to supply necessary medical 
supplies and foods to the infected areas at the peak period of COVID-19 [22].

Different cities across the US are planning to run the pilot program of fully $\mathrm{AVs}$ on various roads. National Highway Traffic Safety Administration (NHTSA), USA, recently published an online tool to track the AV running on the streets [23]. It is predicted that AVs will occupy $25 \%$ of all miles driven in the US by 2030 . The Center for Automotive Research estimated that new autonomous vehicle sales might get increased up to 55 percent by 2040 [24]. The application of automation techniques is not restrained to passenger cars only. Combined efforts of scientists, engineers, and practitioners, to increase efficiency in the shipment of people and goods, initiated to bring public transit and trucks under automation technology [25]. In December 2019, an autonomous freight truck made a trip of 2800 miles in California to deliver butter commercially [26]. Connecticut Department of Transportation (CTDOT) declared the plan of testing the full-size driverless transit bus by 2021 [27].

\section{Effects of CAVs on Transportation Performance}

Implementation of the autonomous vehicle has potential benefits in various aspects. The positive aspects of CAVs are presented in five major perspectives- road safety, highway capacity, mobility, environmental, and economic. Despite having the noticeable progress of automation technology, the implementation of CAVs is facing several issues. Many CAV manufacturers are performing road tests to find out the problems associated with automated driving. Researchers are working to solve the associated problems of CAV deployment from their studies [28-31].

\subsection{Road Safety}

Road safety is a significant consideration for the transition of human drivers to connected and autonomous drivers [32, 33]. Human drivers and their driving habits are the most influential factors of the crash on the road [34, 35]. USDOT surveyed national motor vehicle crash causation and found that about $90 \%$ of car crashes are occurred due to human errors [36]. USDOT fact sheet reported about $80 \%$ of the fatal crashes are due to the impaired connectivity between vehicles. Autonomous driving with connectivity can minimize the drivers' stress [29], and it is expected that AVs will significantly reduce road accidents related to human error [37]. But, the commercialization of AVs has a safety-related key challenge till now. European Commission [32] reported the declination of traffic safety in the mixed mode of nonAVs vehicles and AVs. Wang et al. conducted a statistical survey on the testing of AVs by different manufacturers.
About $63 \%$ of accidents for a total of 3.7 million passing are found to happen in autonomous mode [38]. Fiber et al. found the truck platooning using CACC, moving on the mainline at merging section, has detrimental effects on traffic safety. The regulations for rolling out of CAVs and liability related to road safety have not been addressed properly worldwide [39].

\subsection{Highway Capacity}

The automatic braking configured in the AV system will increase highway capacity along with other advantages. This increased capacity may further induce an overuse of the practical roads, reducing the safe distance between vehicles and increasing vehicle speed due to the incorporation of ACC and CACC [40, 41]. Commercially deployed AVs reduce traffic congestion delays and subsequently increase traffic flow [42, 43]. Applications of ACC and CACC systems in AVs increase highway capacity by $80 \%$ compared to human-driven traffic [44]. Virginia departments of transportation (DOT) found the increment in highway capacity as $28 \%$ and $92 \%$ compared to legacy vehicles for fully AVs and CAVs, respectively. Autonomous trucks (ATs) in freight transportation systems might be beneficial for transportation stakeholders [45]. Calvert et al. showed that low-level automation negatively affects traffic flow and road capacity from the experimental analysis [46].

\subsection{Mobility Benefits}

Improvement in mobility is the consequence of the CAV and this improvement leads to a reduction in traffic congestion and emission [47]. The movement of AVs on the road appears to increase the mobility of elder or disabled people. This application will help disabled peoples access to educational institutions and employment facilities [29]. The ride-sharing tendency of the passengers will be increased with the deployment of CAVs [48, 49] and appear to be economically viable $[50,51]$. The users with disabilities are still in doubt about the acceptance of this new technology. Bennet et al. conducted a questionary survey to know the concerning issue of the people with disabilities about the AVs and found that two-thirds of them have negative views about the use of AVs [52].

\subsection{Environmental Benefits}

AVs are found to be a beneficial option from the safety and mobility perspectives. The environmental benefits are expected to increase in deploying CAVs by reducing traffic congestion and smoothening traffic from minimizing stopand-go driving behavior [53]. The use of the dampening function in place of stop-and-go has the capability to reduce 
GHG. This percentage in GHG decrease was observed to be in the range of $15-\mathrm{S} 73 \%$ [54]. There is a lower possibility to obtain the optimized GHG emission in the near future for the low CAV penetration rate in the roadway [55]. Patella et al. integrated traffic simulation and noise assessment tools and observed a significant reduction in noise pollution for $100 \%$ AVs [56].

\subsection{Economic Benefits}

The incorporation of automation in driving sectors is beneficial from an economic point of view. The economic benefits of the CAVs are associated with reduced congestion and reduced travel time, and its reliability [57]. The comparative cost analysis between the truck platooning of human drivers and autonomous drivers showed the maximum cost reduction as $46 \%$ for 16 -ton trucks [58]. There is a significant reduction in fuel usage due to the platooning of ATs due to the aerodynamic force $[59,60]$. ATs will benefit the transportation system through the improvement in operational frequency in moving goods and overcoming the shortage of truck drivers [61]. This platooning of AT can significantly affect pavement performance due to lane centering tendency [61]. AVs could be economically disadvantageous due to increased travel of minors, elderly and disabled people, and avoiding public transport who do not like ride-share.

\section{Technological Accomplishment for CAVs}

Despite having differences in the design of various manufacturers, CAVs move on the road section based on (1) input devices or sensors to perceive the surrounding environments, (2) control systems comprised of advanced software for processing the inputs and making a decision about the travel path, and (3) output devices or actuators for operating steering, wheel, brakes, etc. [62]. Input devices, control systems, and output devices are treated as the AVs' eye, heart, and hands, respectively [63]. Samak et al. [64] presented the system architecture of AV consisting of perception, planning, and control phase. The perception phase uses the sensors' captured data and prior information for mapping (localizing, estimating the state) the surrounding environments. The perceiving estimates are utilized in making a decision and planning a travel path. The control (lateral and longitudinal) phase ensures the trajectory tracking decided in the planning phase.

The perception phase makes use of vision sensors (i.e., Monocular, IR, and Stereo cameras), light detection and ranging (LiDAR), radio detection and ranging (RADAR), ultrasonic sensors, global navigation satellite system (GNSS) [shown in Fig. 1a] for perceiving the surroundings. These sensors can be applied for detection and distance measurement of obstacles, pedestrians, lanes, and traffic signs from the vehicles. GNSS is a satellite-based system and follows a trilateration procedure to localize and navigate a vehicle $[16,65]$. CACC integrates dedicated short-range communication (DSRC) technologies to establish vehicle-tovehicle (V2V) and vehicle-to-infrastructure (V2I) communication [66]. The recently developed vehicle-to-everything (V2X) technology is gaining momentum, being more advantageous in improving safety. Figure 2 shows the functioning of CAVs for moving on the road. Microcontrollers and ECU with various integrated sensors relieve human intervention in controlling vehicles and supporting ADAS deployments [16]. Artificial intelligence, a sort of machine learning and deep learning language, is used for processing a large volume of information generated by different sensors. This AI system assists automated vehicles in decision-making and motion planning.

The control phase is significantly important in an automated driving system and is responsible for the execution of driving the vehicles in the planned trajectory by braking, steering, etc. The entire functions of the control phase of AV are separated as lateral and longitudinal control. Longitudinal and lateral controller systems in AV ensure safe movement on a road lane [67]. Longitudinal control, maintained by cruise controls, works on the vehicle speeds using a brake or accelerator and maintains a safe distance between two vehicles. ACC and CACC are part of the ADAS and reduce the human driver input in the driving of CAV. ACC senses the surrounding condition based on different sensors and operates in speed control and spacing control modes [68]. The integration of DSRC into ACC enhances its performance by establishing communications (i.e., V2V, V2I) with surrounding, leading it to CACC. This longitudinal control strategy in a traffic platoon maintains the shortest possible distance between two vehicles and stabilized speed to improves safety [66]. GNSS technology (Fig. 2) has decimal level accuracy to keep CAV in its lane and maintain a safe distance from other vehicles [69]. Lateral control systems bound the vehicles to be confined in the travelled lane [67]. The travel path of CAV can be off-line, predefined or online to keep away from the obstacles, to change the lanes, etc. [70]. The dynamic lateral control significantly influences the stability of the CAV. The yaw stability control in the vehicle dynamics maintains the lateral stability of CAVs, and this is performed by braking and steering subsystems. The controller system in CAVs instantly controls yaw rate and sideslip angle to allow the vehicles in a specified path by controller and braking [71].

Neumeister and Pape [72] conducted field experiment on commonly available ADASs (ACC, LKS, LCA and LDW) to observe their perception and navigation performance against adverse atmospheric and road weather conditions. The results found the LDW in vision-based system only to 


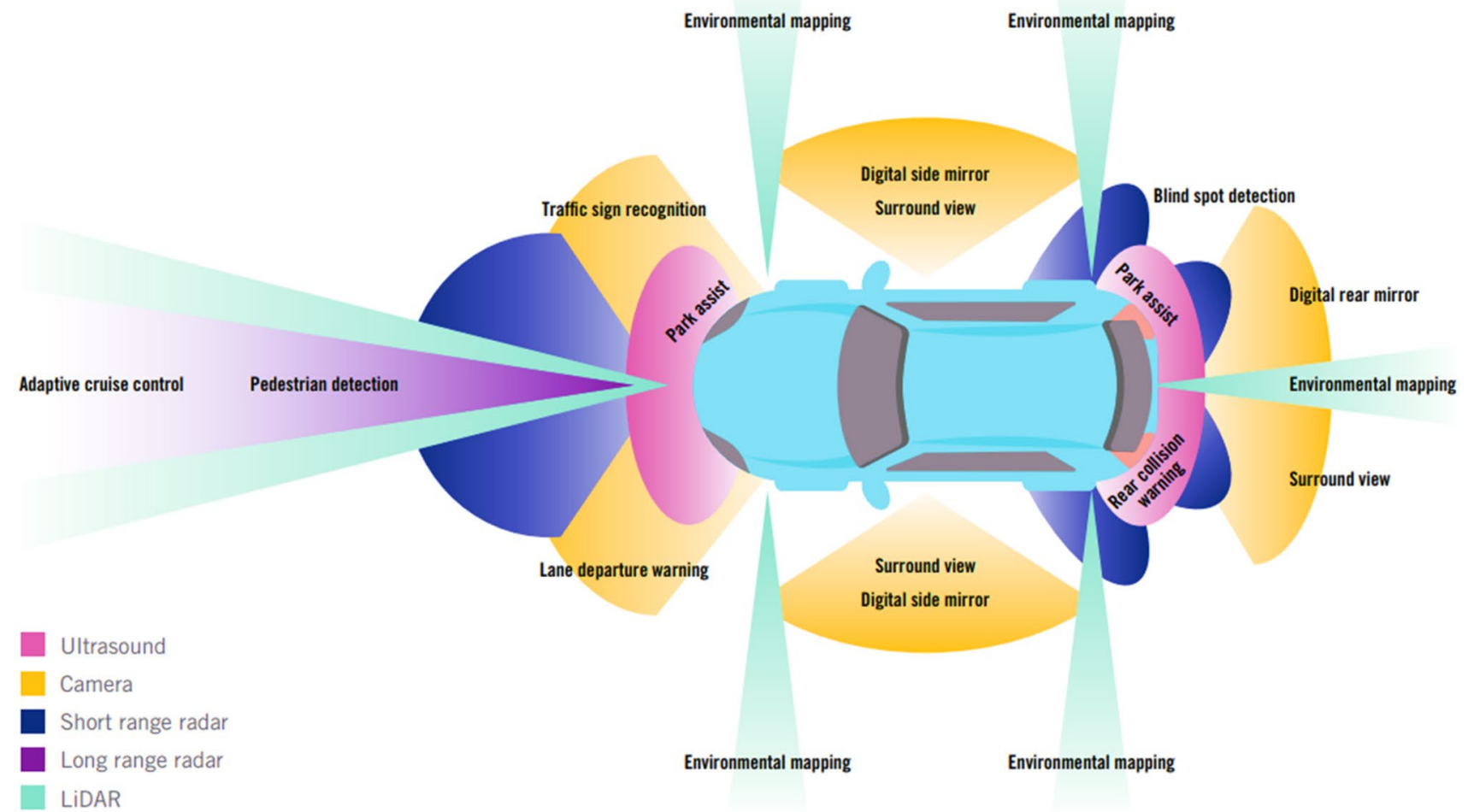

Fig. 2 Positioning performance by AV [16]

be affected due to rain. The ice or snow covering camera and RADAR impaired all considerable ADASs. Vargas et al. [65] reviewed the AV's sensors and their vulnerability at harsh atmospheric weather conditions such as rain, fog, snow, lightning, etc. The functionality of vision-based sensors or camera and their algorithms become degradable at the time of snow, heavy rain and lightning. There is negative effects of fog and severe rain on the visibility performance of LiDAR, RADAR and ultrasonic sensors. The harsh weather creates obstacles in AVs' movement by confusing sensors, hiding the markings. GNSS is a satellite-based technology and local weather has no effect on the positioning performance $[65,72,73]$. The positioning performance of GNSS integrated with Level 2 ADASs successfully overcome the problems associated with complex maneuvers like change of lane, navigation of interchanges [74]. GNSS also faces difficulties running on the road section due to harsh weather conditions in space, not in the atmosphere [59]. The performance of GNSS was not studied in mixed traffic scenario also.

The operational difficulties of autonomous features in vehicles are evident against avoidance of accident or maintenance zone [5, 75] and security [76]. The maintenance and accident zone of a road is redirected using small traffic cones. The camera on the moving vehicles, even space-based technology, is incapable of detecting these small cones.
Camera and LiDAR patching with machine learning technologies can resolve the mentioned issue. The application of this patching is limited due to expensive LiDAR and requirement of many systems in machine learning technology [5]. Wang et al. [5] introduced efficient and cost-effective camera based system with image processing algorithm. This machine vision system performed in a proper way to detect traffic cones of red, yellow and blue colors, and navigating lane smoothly. The introduction of V2X and GPS, one module of GNSS, will facilitate the connectivity between vehicles and roadside infrastructures. Malicious intrusion might be the security concern for connectivity established in CAVs.

Filho et al. [67] introduced a simple control system from the combination of lateral and longitudinal controller for the improvement of road safety. The dependency on a less number of control parameters made it easy for setting up. The effect of rolling resistance and air drag in longitudinal control was neglected to simplify this model. These parameters have considerable effects on the speed control of vehicle. The lateral movement of AVs was smoothened using kinematic controller by Dominguez et al. [70]. This controller improves comfort without considering the reduced performance. Liu et al. [66] integrated advanced CACC algorithm in a platoon and observed the improved platooning performance with the enhancement of string stability. 
Longitudinal stability and the effects of adverse weather on $\mathrm{V} 2 \mathrm{~V}$ in this cooperative system was not taken into account. Norouzi et al. [71] presented sliding mode controller in AV for changing lane. The dynamic aspects of AVs was not taken into account. Mahdinia et al. [68] conducted field test and observed the impacts of mixed traffic containing conventional, ACC, and CACC on transportation system performance. CACC was found to be energy-efficient and emission reducer, rather than ACC and conventional vehicle. The string stability is the great influencing factor of energy efficiency and emission control in a traffic platoon. But, this field study did not consider string stability in this analysis.

\section{Physical Infrastructures for CAVs}

Improvement in road infrastructures for the deployment of CAVs is crucial. The most visible development in automated driving for passenger and freight transport is related to digital infrastructure [77]. The physical infrastructures as the facilitators of the CAV driving are in the planning/study phase. Planners, designers, engineers, and other road stakeholders continue their studies to obtain the probable impacts of CAV on physical infrastructures and find the way out of these limitations. The United States Transportation Research Board, coordinated with the National Cooperative Highway Research Program through Project No. NCHRP 20-24(112) for the development of connected roadway classification system (CRCS) for American Association of State Highway and Transportation Officials (AASHTO). This research program developed the framework with three approaches concerning infrastructure readiness of CAVs for various DOT, metropolitan planning organizations, and infrastructure owners/ operators. The concerning three approaches for the development of the infrastructure facilities are-

- Talking with the road: The improvement in the roadway infrastructure [i.e., dedicated short range communications (DSRC), C-V2X)] for the establishment of the communication of AVs with infrastructures (V2I) and other vehicles $(\mathrm{V} 2 \mathrm{~V})$ on the road.

- Seeing the road: The enhancement of traffic signals and road markings to make it visible to the eyes (i.e., video camera, optical sensors) of the AVs.

- Simplifying the road: The change in road geometry, the improved pavement design, making the pavement free of defects, etc., to obtain operational design domain (ODD) are part of this approach.

The CSRC recommended implementing these approaches in different stages over the next 10 (ten) years for the safe operation of CAVs [78]. European Union (EU) published the European Technology Platform (ERTRAC) roadmap for the development of roadway infrastructures to accommodate CAVs along with human-driven vehicles. The ENTRAC roadmap introduced infrastructure support levels for automated driving (ISAD) and exhibits infrastructure readiness by classifying it into five levels (A-E). Levels $\mathrm{E}$ and $\mathrm{D}$ are called conventional infrastructures and Levels $\mathrm{C}-\mathrm{A}$ are termed as digital infrastructures [79].

The roadway traffic control devices are the essential physical infrastructures and provide the regulatory, warning, and guidance information for driving safely on the road [80]. Road signs and markings are the basic infrastructure needs for the deployment of CAVs. The CAVs, equipped with cameras and sensors, navigate the travel path with the assistance of pavement markings [4]. The centerline and edge line markings are the indicators for AVs to confine the vehicles within the lane [81]. The lane marking inconsistency is the cause of declination in driving by AVs. The unreadable and non-standardized signs create a confusing situation for road users [82]. The geometric design and structural design of pavement infrastructures are discussed in the next section of this paper.

\subsection{Impacts of CAVs on Highway Geometric Design}

The highway geometric design is the controlling factor of operational efficiency and highway safety in the surface transportation system. The geometric design deals with dimensions and layouts of the visible features. The alignment, sight distance, cross-section and intersection are generally considered as geometric features. Washburn and Washburn explained vehicle performance and sight distance as the significant influence factors on highway geometric design [83]. The LiDAR and vision sensors in AVs show lower performance than human eyes in case of obstacles around the horizontal curve and the vertical curve. Washburn and Washburn [83] mentioned that connectivity (V2X) integrated into AVs could solve sight distance problems. But, the fallen boulder on the highway or vehicles with nonoperational V2X on the highways would be problematic for sight distance with the integration of V2X. The adhesion between the rubber tire of AVs and pavement surface affects the acceleration and deceleration rate, inducing lower vehicle performance for on-ramp and off-ramp steepness. The improvements in braking, achieving a higher coefficient of adhesion in the future, will increase the acceleration rate.

The roadway capacity increment is expected for autonomous vehicles by allowing more lanes in the same carriageway through narrowing down the lane width [84]. Garcia and Camacho-Torregrosa [81] compared the influence of lane width on the human-driven and semi-AVs' (Levels 2-3) performance and found semi-AV's failure on the narrower lane width. The authors concluded the $100 \%$ efficiency of human and semi-AV for the lane width of 
$2.5 \mathrm{~m}$ and $2.75 \mathrm{~m}$, respectively. The lane-keeping system (LKS) was deployed in semi-AV for road testing in Spain for this study and the technical reason for this disengagement was unknown. Binshuang et al. [85] observed that reduced lane width and limitation of vision sensors in downhill or uphill affect the safety of AVs. The reduced lane width causes a reduction in superelevation run-off, and subsequent skid resistance is compromised. The sensors have limitations in capturing the road surface conditions in a hilly road. The authors recommended increasing skid resistance to solve the issues and provided the modified braking distance formula to improve traffic safety. The authors introduced Eq. 1 from the regression analysis of the field test data to obtain the side-force coefficient (SFC). SFC is the measurement of the ability to control the vehicles in the curve. The obtained SFC is used in Eq. 2:

$$
\begin{aligned}
\mathrm{SFC} & =-0.85 t^{2}+3414 t-\left(3 \times 10^{6}\right) ; \\
R^{2} & =0.9919, \\
\varphi(t) & =0.01(\mathrm{SFC}),
\end{aligned}
$$

where, $t$ is the attenuation period of SFC (years), $\varphi(t)$ is the frictional coefficient of tire-pavement interface.

The frictional coefficient is inputted in Eq. (3) to determine stopping distance $(D)$. This equation was adopted from Chu and Fwa (2018),

$D=v_{0} t-\frac{1}{2} G g t^{2}-\int_{0}^{T}\left[\int_{0}^{t} \varphi(t) g \mathrm{~d} t\right] \mathrm{d} t$.

The American Association of State Highway and Transportation Officials (AASHTO) [86] provided the design criteria for different geometric elements of the highways. The guidelines introduced Eqs. (4) and (5) for stopping sight distance $(S S D)$ (i.e., the distance to stop the vehicle before the stationary object). All Eqs. $(4,5)$ presented here are valid for metric units only.

SSD on level roads:

$\mathrm{SSD}=0.278 V t+0.039\left(\frac{V^{2}}{a}\right)$.

SSD on the sloping road:

$\mathrm{SSD}=0.278 V t+\frac{V^{2}}{254\left[\left(\frac{a}{9.81}\right) \pm G\right]}$,

where, $V$ is the design speed $(\mathrm{km} / \mathrm{h}), t$ is the driver's perception reaction time (seconds),

$a$ is the deceleration rate $\left(\mathrm{m} / \mathrm{s}^{2}\right), G$ is the roadway grade (decimal).
AASHTO recommends the perception reaction time (PRT) and deceleration rate as $2.5 \mathrm{~s}$ and $3.4 \mathrm{~m} / \mathrm{s}^{2}$ to evaluate SSD. The PRT of full AVs was found to be in the order of $0.5 \mathrm{~s}$ from the extensive numerical study [87]. Khoury et al. [88] used AASHTO models to find out length of sag and crest curve for the changed value of the reaction $(0.5 \mathrm{~s})$ and perception time (2.5 s). But Chris et al. [89] evaluated perception reaction time of AV was $0.2 \mathrm{~s}$. AASHTO adopts Eqs. (6) and (7) and Eqs. (8) and (9) for the length calculation of the crest curve $\left(L_{\text {crest }}\right)$ and sag curve $\left(L_{\text {sag }}\right)$ based on sight distance $(S)$ and recommends the height of the driver's eye above the roadway surface as $1.08 \mathrm{~m}$ and headlight height as $0.6 \mathrm{~m}$.

When $S<L_{\text {crest }}$ :

$L_{\text {crest }}=\frac{A S^{2}}{100\left(\sqrt{2 h_{1}}+\sqrt{2 h_{2}}\right)^{2}}$.

When $S>L_{\text {crest }}$ :

$L_{\text {crest }}=2 S-\frac{200\left(\sqrt{2 h_{1}}+\sqrt{2 h_{2}}\right)^{2}}{A}$.

When $S<L_{\text {sag }}$ :

$L_{\text {sag }}=\frac{A S^{2}}{[200(H+S \tan \beta)]}$.

When $S>L_{\text {sag }}$ :

$L_{\text {sag }}=2 S-\frac{[200(H+S \tan \beta)]}{A}$,

where, $h_{1}, h_{2}, \beta$ is the height of the driver's eye, object, and headlight above the roadway surface. $\beta$ is the angle of inclination of the headlight beam shown in Fig. 3.

The AVs replace the human eyes with vision sensors such as LiDAR. The height of human eyes or vision sensors, the inclination angle and the perception range are important parameters of human driver as well as AVs to perceive surrounding environment. The $h_{1}$ of AVs is obtained by summing the height of the Waymo driverless car $(1.55 \mathrm{~m})$ and the height of LiDAR $(0.28 \mathrm{~m})$. Khoury et al. [88] assume the minimum $h_{1}$ value as $1.7 \mathrm{~m}$ keeping freight transport height in mind. Velodyne LiDAR Inc. [90], a manufacturer of LiDAR, has a total angle of view from the horizontal axis of $26.8^{\circ}$ as shown in Fig. 4. Khoury et al. [88] consider half of the manufacturer-provided angle as the inclination angle $\left(13.4^{\circ}\right)$.

Khoury et al. [88] redesigned the roadway for the proposed values of AVs mentioned in the previous section. AASHTO recommendation for the minimum vertical curve length was followed to ensure drivers' comfort. Authors neglected the effect of CAVs on the horizontal curve of 


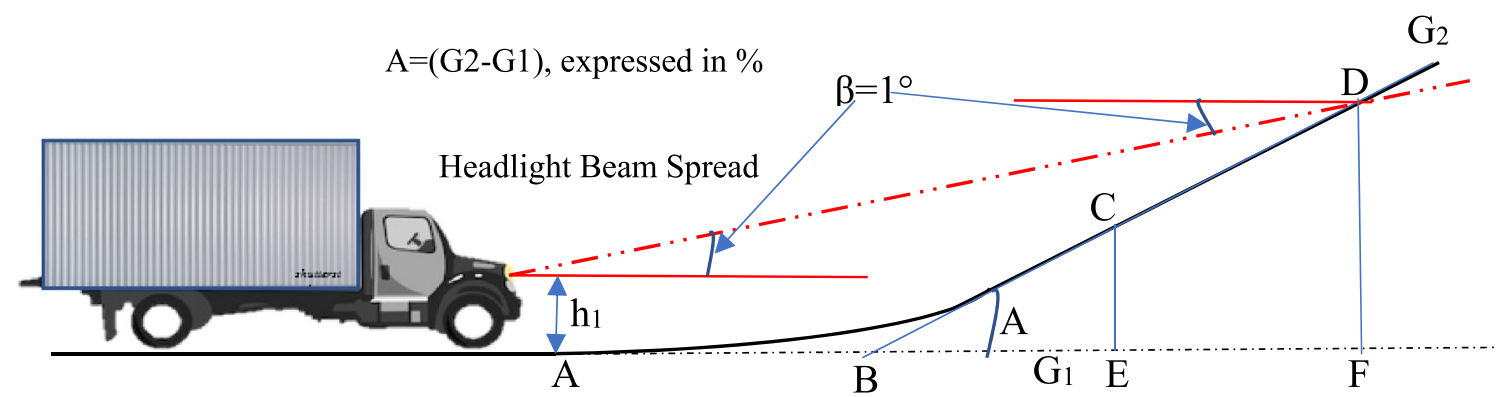

Fig. 3 Inclined angle of the headlight beam [88]

Fig. 4 Vertical field of view of LiDAR sensor ( adapted from Velodyne LiDAR Inc. [90])

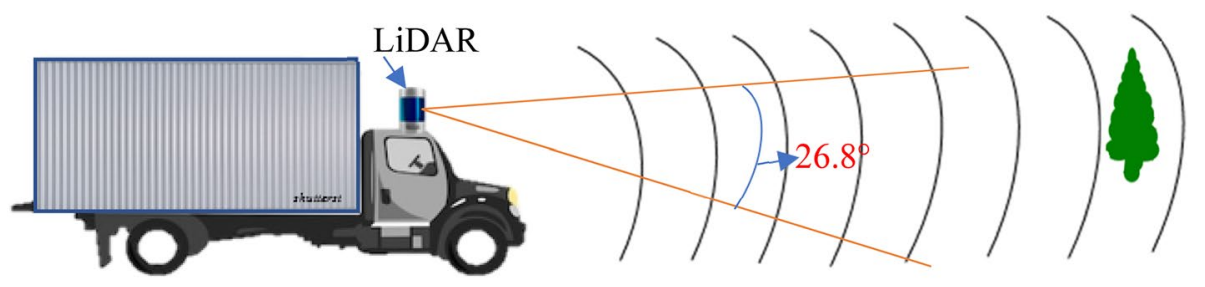

Fig. 5 Profiles for different designs [88]

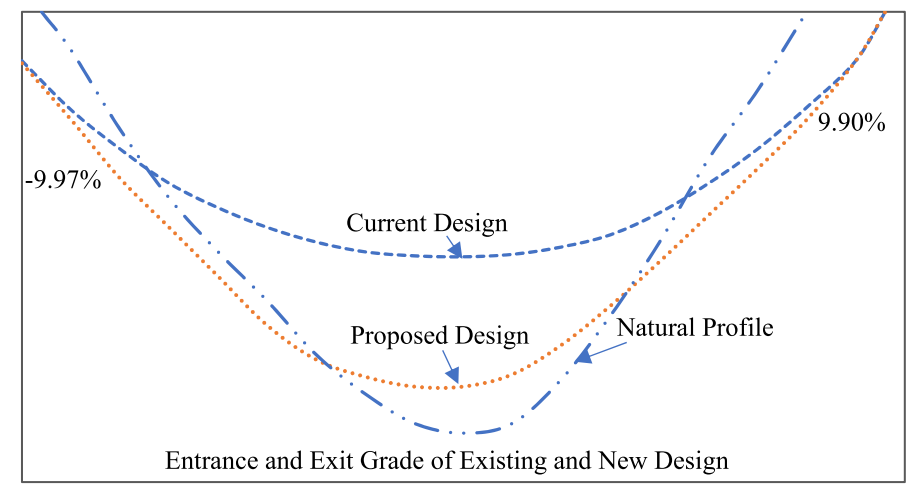

a highway. The current geometric elements following the AASHTO standard were compared with the redesigned values. The authors found a significant reduction in $S S D, L_{\text {crest }}$ and $L_{\text {sag }}$, and an improvement in economic perspectives for less earthwork (lowering $7.67 \%$ filling and $47.22 \%$ cutting) shown in Fig. 5.

Welde and Qiao [91] also re-evaluated $S S D, L_{\text {crest }}$ and $L_{\text {sag }}$ for two AV scenarios and found a significant influence on geometric elements. In addition to all parameters of Kohury et al. [88], the authors considered the deceleration rate as $4.5 \mathrm{~m} / \mathrm{s}^{2}$ in scenario 1 (A-1). In scenario 2 (A-2), PRT was assumed as $0.2 \mathrm{~s}$ along with a deceleration rate of $4.5 \mathrm{~m} /$ $\mathrm{s}^{2}$. The authors compared the geometric elements of two scenarios (A-1 and A-2) with the AASHTO standard values for human-driven vehicles, as shown in Fig. 6. The author found autonomous driving as an economically efficient option due to the decrease in $S S D, L_{\text {crest }}$ and $L_{\text {sag. }}$. Wang and $\mathrm{Yu}$ [92] performed research on finding out the effects of Level 0-Level $5 \mathrm{AVs}$ on geometric elements (sight distance

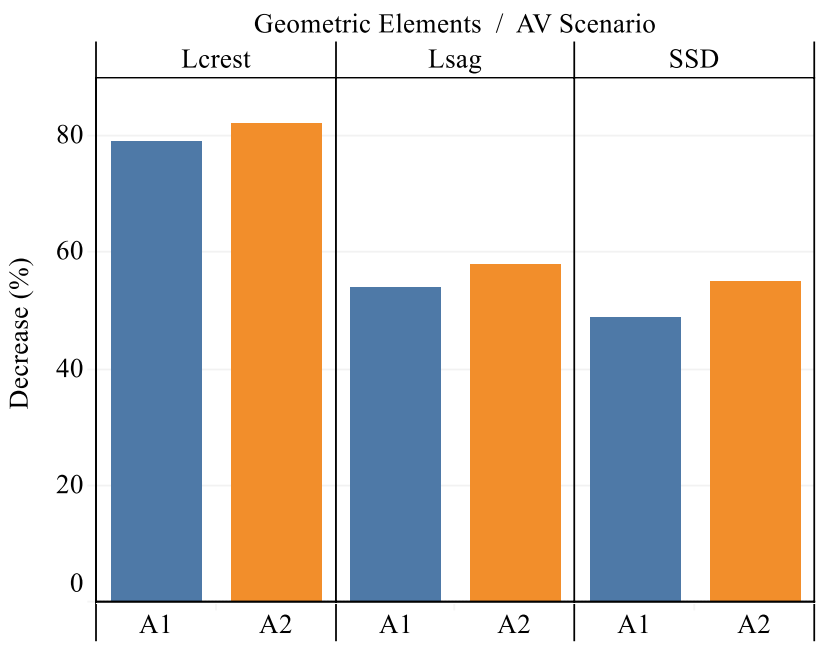

Fig. 6 Percentage decrease in geometric elements [91] 
and length of vertical curve) of a road. This was assessed for the proper design criteria such as reaction time, acceleration. Authors observed the reduction in $L_{\text {crest }}$ and $L_{\text {sag }}$ with the increment of autonomy level. The LiDAR sensor, manufactured by Waymo, was incorporated in analyzing the road geometric features. The height of LiDAR sensors and inclination angle vary with different manufacturers. The use of specific LiDAR for evaluating sight distance and length of vertical curves cannot draw generalized conclusion. The discussion presented in Sect. 4 exhibits that proper working of sensor can be affected due to adverse weather conditions. The adverse weather and complex scenario at the moment of driving were not considered in this study.

\subsection{Effects on Pavement Structural Performance}

The deployment of CAVs will influence the structural performance of pavements due to reduced wheel wander and platooning of truck traffic. The lane-keeping algorithm will accomplish the wheel moving in a narrower path and platooning will reduce inter-vehicle distance.

\subsubsection{Human Driven vs Autonomous Vehicles}

Human drivers almost always change the lateral positioning of vehicles on a lane of road section during the traveling period. This lateral movement of the wheel along lane width is referred to as wheel wander. The controlling factors of wheel wander are drivers' habits, wind effects, and mechanical alignment [93] and lane width, vehicle width, speed, and presence of patching and rut on the road [94]. Researchers found that wheel wander of vehicular movement could be modeled with probabilistic distribution [95, 96]. Lateral positioning of the wheel on the travelled lane is normally distributed [97-99] and is statistically modeled with zero mean and known standard deviation following Eq. 10 [100],

$f(x)=\frac{1}{\sqrt{2 \pi \sigma^{2}}} e^{-\frac{(x-\mu)^{2}}{2 \sigma^{2}}}$,

where, $\mu$ is the mean of variables, $\sigma$ is the standard deviation of wheel wander.

Mechanistic-empirical (ME) pavement design analyzes the pavement section for the human-driven vehicle for wheel load normally distributed on a lane with zero mean and standard deviation of $0.25 \mathrm{~m}$ (10 in.) [97]. This standard deviation value differentiates human-driven vehicles from autonomous and semi-autonomous vehicles concerning the loading distribution pattern. Autonomous vehicles are bound to follow the centerline of pavement lanes due to the integrated dynamic control system [101]. This lane-centering tendency compels the lateral positioning of the wheel load to a narrower width, resulting in channelized traffic. This type of channelization for autonomous vehicles is analyzed as zero wander distribution [102]. Zhou et al. quantified wheel wandering of AVs and the standard deviation of wandering was found to range $3.0(\mathrm{~cm})$ to $7.5(\mathrm{~cm})\left(1.2^{\prime \prime}\right.$ to $\left.3.0^{\prime \prime}\right)$ for AV. The author concluded with three-times narrower standard deviation could be modeled for AVs to analyze the pavement section [103].

\subsubsection{Wheel Wander in Pavement Analysis}

Mechanistic-Empirical Pavement Design Guide (MEPDG) software, also known as AASHTOWare, is widely accepted to predict pavement distresses. This robust pavement analyses pavement performance based on four major input groups. These inputs are material properties for all the layers, traffic details, climate, and structural design parameters. Wheel wander, one of the traffic inputs, controls the wheel loading distribution in the pavement lane. The MEPDG approach evaluates the fatigue cracking in pavement by dividing the width of the lane into five portions, as shown in Fig. 7. The center positioning of truck traffic is fixed and calculated by multiplying standard deviation with standard deviates $(0$, $\pm 0.5244, \pm 1.28155$ ). About $20 \%$ of all the wheel movement is addressed in predicting fatigue for each segment. Damage accumulations from segments $1-5$ are represented as D1, D2, D3, D4, and D5. Cumulative fatigue damage is evaluated using Eq. 11. No explanation of modified rutting determination procedures is given in the MEPDG guide [100]:

$D=0.2 D_{1}+0.2 D_{2}+0.2 D_{3}+0.2 D_{4}+0.2 D_{5}=0.2 \sum_{1}^{5} D_{i}$.

The permanent deformation of the asphalt concrete layer for roads (PEDRO) model is a linear viscoelastic program. Said et al. [104] developed the PEDRO model based on the results of the shear box test of the AC mixture. This model is particularly used to evaluate the rutting of AC layers [104, 105]. The accumulated rutting in AC pavement from the PEDRO model and field observations for different wheel wanders are in good agreement [106].

\subsubsection{Pavement Distresses and CAT}

Many researchers reported that the structural performance of pavement is significantly affected by the movement of heavy truck traffic resulting in the reduction of pavement life [107, 108]. Furthermore, channelization of connected and autonomous truck (CAT) system increases loading repetition on the narrower width of the lane compared to human-driven vehicles [102]. The increased load repetitions induce the accumulation of pavement distresses [29]. In-situ pavement 
Fig. 7 MEPDG analytical approach for wheel wander [97]

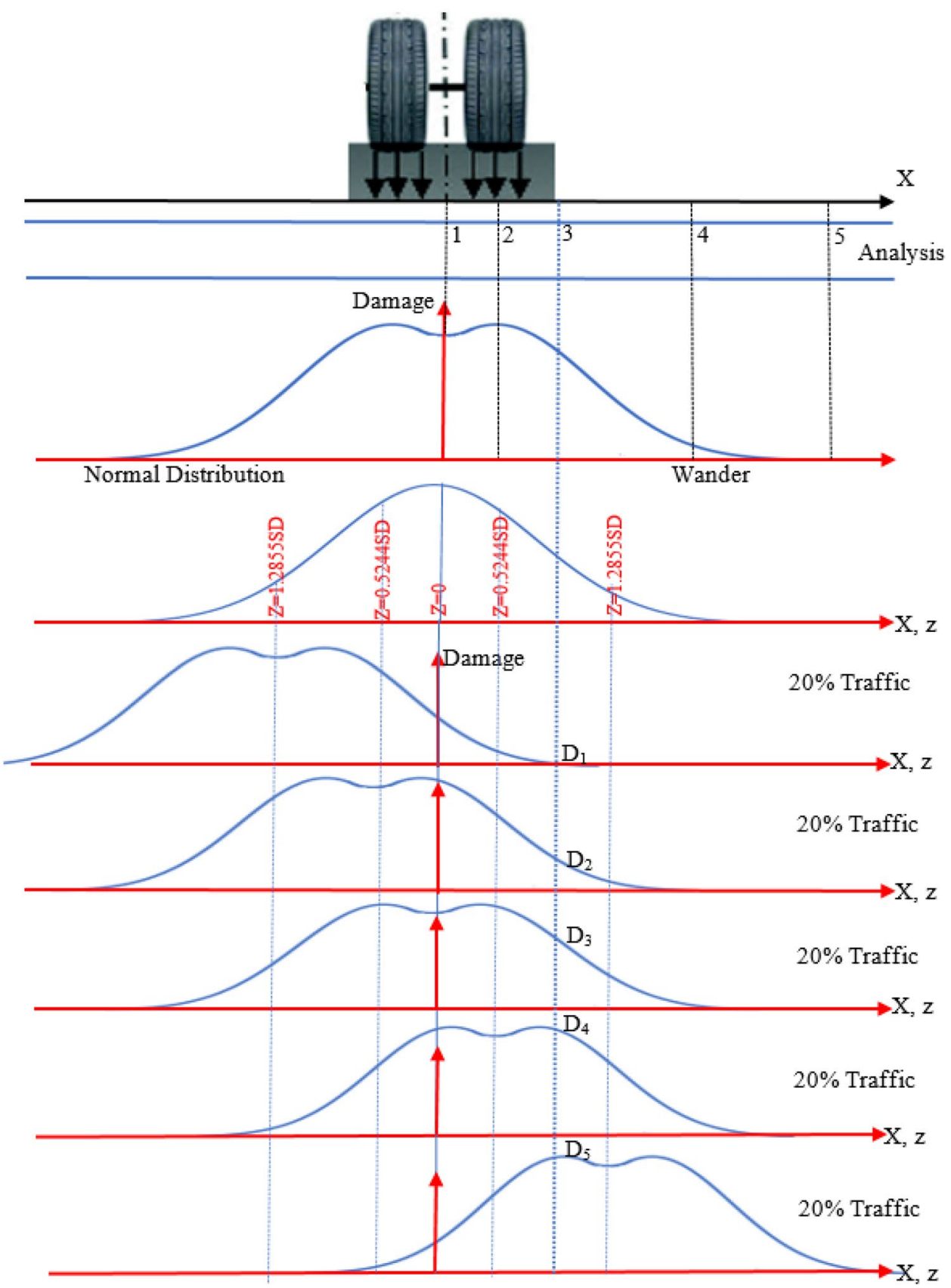

tests showed significantly higher responses for the reduction of wheel wandering on the pavement lane [109]. The observable longitudinal tensile and vertical compressive strain was found to be inconsistent with MEPDG output in this study. Said and Hakim [110] found that increase in wheel wander from 0 to $0.125 \mathrm{~m}$ would result in $38 \%$ reduced rutting. The PEDRO program used in this analysis only evaluates AC rutting. This analysis was not validated for a wide range of traffic loading and climatic conditions. Multi-linear elastic analysis of a typical pavement section showed that lower load repetitions of zero wander vehicles compared to humandriven vehicles (2.1 times lower for rutting and 1.1 times lower for fatigue) would induce equal pavement distress [102]. Authors determined pavement performance for human driven vehicles, mixing of AV and non-AV on the same lane, and AV on the dedicated lane. Traffic input in MEPDG was modified the different scenario and no interaction between $\mathrm{AV}$ and non-AV was considered.

Wu and Harvey [99] conducted heavy vehicle simulator tests and modeled a testing system to estimate the effect of traffic wander on rutting. Traffic wander induced $56 \%$ more rutting in the pavement section than non-wander traffic. The exclusion of plastic volumetric deformation bound to occur the highest rutting at the side of the calculated profile. Zhou 
et al. [103] performed field tests to evaluate the impact of AT on fatigue and rutting of AC pavement. Predicted data showed that AT reduces fatigue life and rutting life of AC pavement by $20 \%$ and $32 \%$, respectively, compared to the human-driven truck. This field test was performed for moving only single AV. This study was limited to AV movement on asphalt pavement, no solution was presented for mixed traffic (AV and non-AV) condition. The substantial increment in rutting and fatigue crack is also observed from the simulation of AC pavement by Chen et al. [111]. Rana [112] and Rana and Hossain [113] performed a study to observe the effect of different loading distribution of vehicles (wheel wander) on AC rutting, as shown in Fig. 8. Authors found that AT with no lateral movement has a significant contribution in the increase of AC rutting (more than 200\%). These studies considered fully AV for distress evaluation. Fully AV will take longer to be on the public platform. The effect of the mixing non-AV and AV on pavement was not considered. The integration of technology and structural performance was missing.

The number of connected trucks driving at a close distance is said to be truck platooning. The trucks in a platoon can be connected in any of (1) longitudinal directions, (2)

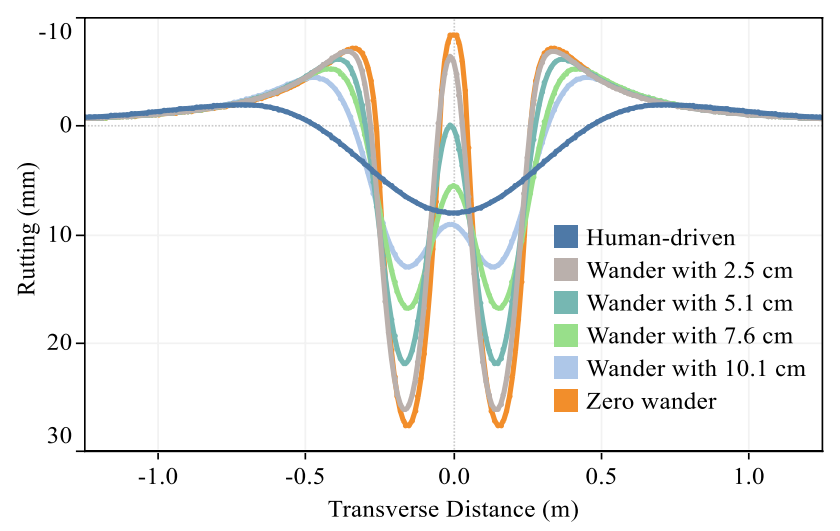

Fig. 8 Rutting profile in transverse direction for different simulations [112] both longitudinal and transverse directions, (3) coupled in longitudinal and transverse direction using cruise control. The CACC is incorporated in the third scenario use and all trucks follow the same track. Platooning in freight transport is gaining feasibility with the introduction of CAT technologies. Despite increasing safety, fuel savings, and emission control, truck platooning has a significant negative impact on pavement performance $[60,61,114]$. The reduced healing time of asphalt concrete from the close inter-truck distance and channelization of truck loading causes asphalt pavement deterioration for truck platooning [35, 61]. Bouchihati [35] found that more rutting and fatigue cracking of $\mathrm{AC}$ pavement in coupling of trucks in both the longitudinal and transverse directions in a platoon and leading truck follows same track using cruise control.

\subsubsection{Optimization of Autonomous Vehicle Movements and Distresses}

Few researchers have recently developed strategies to optimize the additional pavement distresses accumulated for the movement of AT. Researchers mainly focused on controlling the wheel loading distribution and vehicle positioning on the pavement lane explicitly [102, 115, 116]. Noorvand et al. [102] modified the traffic input in the Mechanistic-Empirical Pavement Design Guide (MEPDG) software to incorporate AT in pavement design. Load equivalency factors (LEF) for wheel loading distribution on a traffic lane and vehicle positioning (the combination of AT and non-AT in the same lane) on different lanes of road sections were calculated. LEF was evaluated for zero wander and uniform distribution of wheel loading (shown in Fig. 9) on the lane comparing with human-driven vehicles. Analyzed data showed a significant reduction of fatigue and rutting for uniform distribution of wheel load covering the entire width of the lane. Zhou et al. [103] also found improved pavement performance for uniform wheel loading distribution on the pavement lane. The authors observed from the field testing that the standard

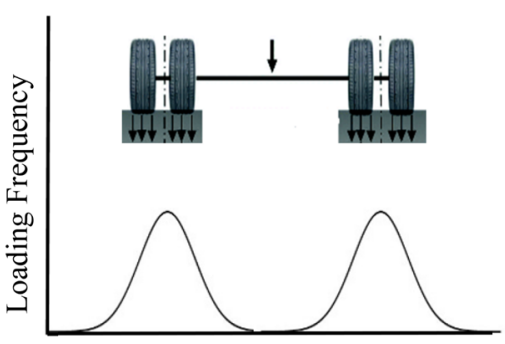

Lane of Road

(a)

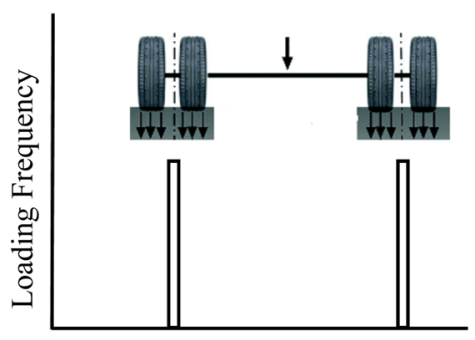

Lane of Road

(b)

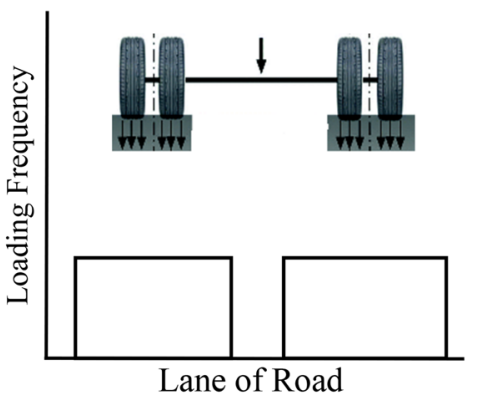

(c)

Fig. 9 Loading distribution of $\mathbf{a}$ human-driven, $\mathbf{b}$ autonomous and $\mathbf{c}$ uniform distributed vehicles (Adapted from [102]) 
deviation for wheel loading distribution of AT along the lane width is three times narrower than human-driven vehicles.

Chen et al. [111] predicted fatigue and rutting for zerowander, uniform, double peak Gaussian, and two-section uniform mode distribution of wheel load (distributions shown in Fig. 10) on the lane of pavement. The finite element analysis was deployed to observe the effects of lateral distribution of autonomous trucks within the lane. The authors found that the two-section uniform mode distribution of wheel loading distribution significantly reduced rutting and fatigue of AC pavement.

In another study, Chen et al. [116] proved fatigue growth mode as an efficient approach to control AT laterally on the pavement lane. In this mode, the ATs are directed to move in the different lateral positions of the road based on the fatigue damage. The sensors placed on the pavement ensures the effect of ATs on the pavement and their position accordingly. This lateral control mode minimizes fatigue damage growth by $28 \%$ for $100 \%$ of autonomous vehicles.

Gungor and Al-Qadi [61] introduced a centralized control strategy to control the positioning of AT platoon on the pavement lane. This strategy explicitly controls the positioning of the platoon using V2I communication (Fig. 11) for the increase in the wander of AC pavement. The authors found a significant minimization in pavement damage and an increase in pavement life from the application of this strategy. The application of this strategy showed a 50\% reduction in life cycle cost in a case study. Bouchihati [35] suggested smart lanes equipped with sensors for distress optimization and these sensors will explicitly control the positioning of the platoon for improving pavement performance. Marsac et al. [117] performed a numerical study to increase the wheel wander of truck platooning. Each truck in a platoon was placed in the different transverse directions of a lane. The placement in that way increases the pavement performance. Gungor and Al-Qadi [61] did not provide any performance improvement solution by increasing the resting period. Gungor et al. [60] introduced the platooning-control strategy to obtain the benefits of the increased resting periods (i.e., improvement in self-healing capability) along with wander. This strategy controls the position of the truck platoon (Fig. 12) for distribution of load on the wider lane and inter-vehicle positioning in each platoon to improve the healing period. This strategy was found to reduce the total cost by $9 \%$. Song et al. [118] organized AT platoon in respect to vehicle number, lateral offset and longitudinal interval with consideration of energy saving and fatigue damage. Authors found that platoon with two trucks, having no lateral offset and varying longitudinal interval from 0.5 to 5.0 of single truck length, significantly reduce fatigue and save energy.

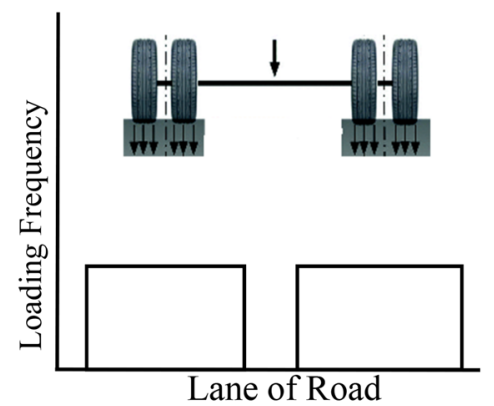

(a)

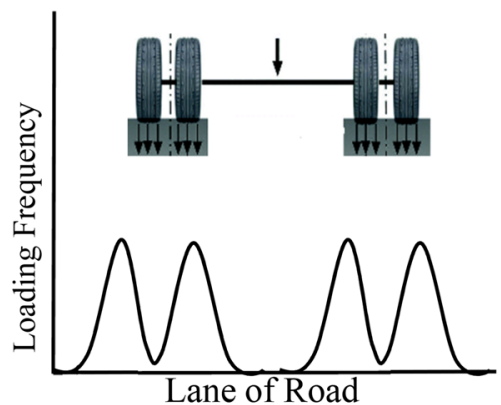

(b)

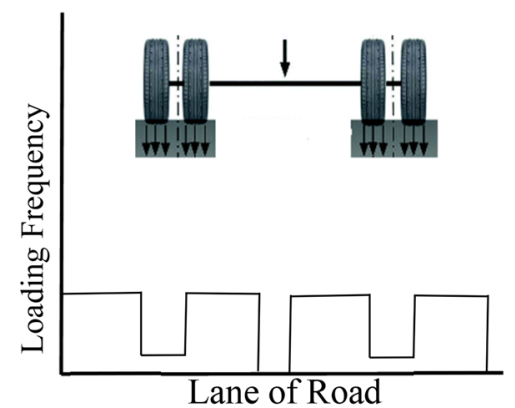

(c)

Fig. 10 Modes of a uniform, $\mathbf{b}$ double peak Gaussian, $\mathbf{c}$ two-section uniform loading distribution (Adapted from [111])

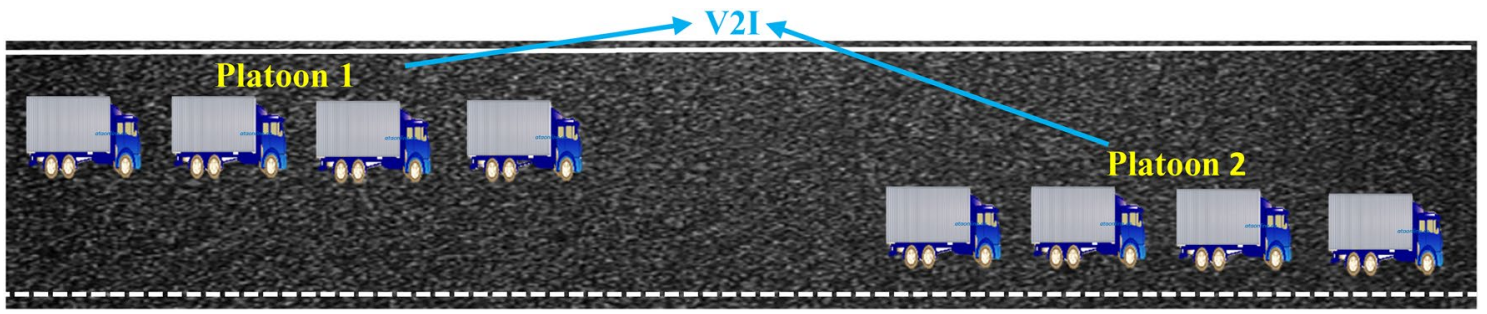

Fig. 11 Optimization of the lateral position of truck platoons (adapted from [61]) 


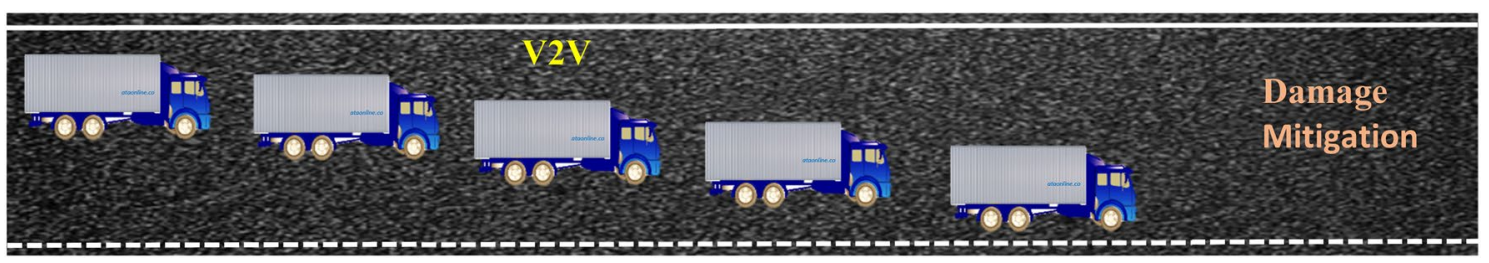

Fig. 12 Decentralized optimization of autonomous trucks in a platoon (adapted from [60])

\section{Summary of Issues in Current Literature}

The design of road infrastructures currently in practice is based on the features of human drivers. Technological progress has successfully integrated various ADASs in vehicles, and these replace the functions of human drivers. Autonomy in vehicles is advancing from Levels 0 to 5 , and the communication module to $\mathrm{AV}$ is moving towards $\mathrm{CAV}$. The deployment of CAVs on a public road has many advantages and various issues related to vehicle automation, transportation performance, technologies, and physical infrastructures. The issues in current literature presented in this article are summarized as,

- The movement of vehicles with integrated ADASs appeared in difficulties at complex maneuvering. The collision of AVs with conventional vehicles, moving at the same speed, was noticeable at traffic sign locations. ACC and LKS in the vehicle were found to be conflicting when the human driver changed the lane and $\mathrm{AV}$ decided to overtake that lane-changing vehicle. Human drivers lack of prior knowledge on driver-assist systems and overreliance on technology can endanger passengers' safety.

- The inconsistencies of autonomy level were observed due to its linear increment with autonomy, inadequate knowledge of human-machine interaction, evaluation of environment, infrastructure and social impacts, and labeling a little activity as Level. The uncertain technological movement creates discrepancies about autonomy level.

- The mixed traffic (mixing of AVs and non-AVs) condition and truck platooning movement on the lane at the merging sections of a road were found to face accidents. More accidents were observed in autonomous mode than non-autonomous mode. The disabled people have not accepted this system positively. Traffic flow and road capacity become affected at low-level automation.

- The operation of AVs has difficulties at the time of avoiding the maintenance zone on the road due to the incapability of detecting small cones by vehicle sensors. The degradability of vehicle sensors in adverse weather is obvious. The bad weather in space is unfavorable for GNSS also.
- The evaluation of sight distance and length of the vertical curve become dissimilar due to the difference in the height of vision sensors or eye and perception time of $\mathrm{AV}$ and conventional vehicles. The inclination angle and height of sensors are variable and have specific values for each manufacturer. Geometric elements assessed for LiDAR of Waymo cannot be used for general purposes. The presented literature in this article observed the avoidance of the impacts of CAVs on horizontally aligned curvature. Researchers working on geometric features of the highway have not considered the influence of adverse weather or complex maneuvering on the components of geometric elements.

- The reduction of wheel wander and less inter-vehicle distance are two key factors affecting the structural performance of pavement due to CAV movement. Researchers are modelling to observe the negative impacts of the AV scenario on pavement performance and their minimization techniques. The studies on the structural performance of fully AV movement are limited to fatigue cracking and rutting. Very little research worked on finding out the effect of partial automation on pavement distresses. Wheel wander was simulated to distribute vehicle loading over the full width of a road. All the studies on minimizing pavement distresses are simulation or numerical-based. Results on laboratory investigation or field tests for minimizing the effects of CAV movement on the pavement are inadequate.

\section{Future Study}

The technological evolution in vehicle automation is advancing rapidly. The integration of driver-assist systems in vehicles is assisting human drivers in various driving functions. Research on field tests clearly depicted the failure of ADASs in adverse weather and complex maneuvering. The investigation of the failure mechanisms of different ADASs is essential. More specifically, the causes of failure at adverse weather or complex maneuvering need to be found out. The perception, planning and control system of automated vehicles can be adjusted accordingly. Weather can be classified 
based on severity level, and the entire ADAS can be adjusted to mitigate the severity.

The CAVs are in the development stage till now. The behavior of CAVs will depend on how CAVs will mimic human drivers. Different countries are conducting road tests to observe the applicability of the commercialization of CAVs. When the AVs commercially move on the road, the performance issues associated with automation will be obvious. Zhou et al. [103] performed a field test and found the standard deviation ranging from 1 to $3 \mathrm{in}$. The improvement in pavement performance can be studied by applying field wheel wander. The CAVs significantly affect the geometric elements of the highway [91]. It might be a good option for researchers to investigate the effects and optimization of the changing geometric elements on pavement distress.

Rutting is one of the dominant distresses in pavement and significantly influenced by traffic and climatic factors [119]. The movement of the CAVs on a narrower lane will increase the pavement rutting. The water is accumulated in the rutted pavement portion in the rainy season. The driving safety and stability of the vehicles are greatly affected at the rutted zone filled with water [120]. The accumulated water causes hydroplaning risk for various vehicles, especially for passenger cars [112]. The hydroplaning risk may interrupt to gain of probable road safety in the wet road from the implementation of CAVs. The inter-connected study of road safety and pavement design might provide a well-accepted solution for this contradictory situation.

Full autonomous driving can run on the road without any human intervention. Human fatigue, major cause of road accidents, will no more issue in the future. The movement of AT at night time might be beneficial for pavement performance. The additional asphalt pavement distress for CAVs can be minimized, allowing AT at night time because asphalt pavement can perform better at the low temperature of the night time. In that case, there is a possibility of fatigue cracking and asphalt rutting to be contradictory. The asphalt pavement performance can be studied to establish optimization for the movement of vehicles at night time.

\section{Concluding Remarks}

The continuous technological developments are accelerating the commercial initialization of connected and autonomous vehicles (CAVs) on the highway. The deployment of CAVs will provide more benefits to transportation sectors. A lot of uncertainties about the benefits of CAVs and the potential impacts on pavement infrastructures are noticeable. The conclusions drawn from the review study is presented below:

- The introduction of the different advanced driver-assist systems (ADAS) is transforming human-driving features to full automation. ADASs integrated with vehicles are not matured and have troublesome situations in practical use. The vehicles with autonomy Level 3 have already been deployed due to technological progress, and the pilot program of the upper version vehicle is running. Few researchers criticized the classification of autonomous vehicles in six levels because of unpredictable technological directions.

- Different sensors and other communication modules perceive the surrounding environment. Artificial intelligence processes the perceiving data for making decisions and planning the way. The lateral controller confines the automated vehicles in a lane and the longitudinal controller assists in maintaining the safest inter-vehicle distance. Adverse atmospheric conditions such as heavy rain, snow, etc., remarkably influence the proper working of various AV sensors.

- The full automation of passenger cars along with freight transport are proved to be advantageous for transportation sectors. The connectivity has added a new dimension to the automation and also induces more benefits by truck platooning. However, several studies reported that there are uncertainties about the gaining of benefits considered for CAVs.

- Connected and automated driving has several adverse effects on pavement infrastructures (digital and physical) and consequent major demands on the adaptation of the infrastructures. Studies on digital infrastructures provided different logical solutions and advancing for more advanced options. However, there is a severe need for transformation of physical infrastructure before deployment of CAVs.

- The geometric elements (stopping sight distance, length of sag curve, length of crest curve) for CAVs are beneficial economically due to the reduction in earthwork. The assessment of geometric elements is not studied at adverse weather or complex maneuvering and needs to be assessed separately for each manufacturer for having a different height of sensors.

- The significant pavement distresses are associated with reduced wheel wander for excessive load repetition on the narrower width of the lane. The control of truck movement in the transverse direction of the lane to induce uniform loading has been proposed as a suitable solution for distress optimization. In addition, double peak uniform distribution, loading distribution at field wander, etc., might improve the pavement performance.

- The more load repetition on reduced lane width and decreased self-healing capacity of the asphalt pavement due to close inter-truck distance accelerates the pavement distress for truck platooning. Researchers proposed strategies to control truck platooning explicitly for transforming disadvantages into opportunities. The explicit control 
by placing the truck platoons at the different transverse location or truck in a platoon at a different location or a combination of both can be beneficial for pavement distress optimization.

- Extensive field and laboratory studies for the evaluation of the effects of CAVs on pavement performance are required to determine and validate the pavement distresses.

Author Contributions Not applicable.

Funding Not applicable.

\section{Declarations}

Conflict of Interest Not applicable.

\section{References}

1. ATKINS. (2017). Analysis of geospatial data requirement to support the operation of autonomous cars. Danish Ministry of Energy, Utilities and Climate. https://sdfe.dk/media/2918928/ geospatialdata_cavs_final_report.pdf.

2. Sweatman, P., \& Peak, M. (2017). State CEO Leadership Forum on Connected \& Autonomous Vehicles and Transportation Infrastructure Readiness in Conjunction with 2017 ITSWC, Montreal, Canada. Report Number NCHRP Project 20-24, Task 111. National Cooperative Highway Research Program.

3. Shladover, S. E. (2018). Connected and automated vehicle systems: introduction and overview. Journal of Intelligent Transportation Systems, 22, 190-200. https://doi.org/10.1080/15472450. 2017.1336053

4. Hallmark, S., Veneziano, D., \& Litteral, T. (2019) Preparing local agencies for the future of connected and autonomous vehicles, Minnesota Department of Transportation. http://mndot.gov/resea rch/reports/2019/201918.pdf.

5. Wang, L., Sun, P., Xie, M., Ma, S., Li, B., Shi, Y., \& Su, Q. (2020). Advanced Driver-Assistance System (ADAS) for intelligent transportation based on the recognition of traffic cones. Advances in Civil Engineering. https://doi.org/10.1155/2020/ 8883639

6. Lengyel, H., Tettamanti, T., \& Szalay, Z. (2020). Conflicts of automated driving with conventional traffic infrastructure. IEEE Access., 8, 163280-163297. https://doi.org/10.1109/access.2020. 3020653

7. American Automobile Association. Advanced Driver Assistance Technology Names: AAA's Recommendation for Common Naming of Advanced Safety Systems. https://www.aaa.com/ AAA/common/AAR/files/ADAS-Technology-Names-ResearchReport.pdf.

8. Mitchell 1. (2019). All about ADAS. https://mitchell1.com/shopc onnection/all-about-adas/. Accessed on 5 Oct 2021.

9. Ucińska, M. (2021). Adaptation to driver-assistance systems depending on experience. Open Engineering, 11, 650-661. https://doi.org/10.1515/eng-2021-0064

10. Noble, A. M., Miles, M., Perez, M. A., Guo, F., \& Klauer, S. G. (2021). Evaluating driver eye glance behavior and secondary task engagement while using driving automation systems.
Accident Analysis and Prevention, 151, 105959. https://doi. org/10.1016/j.aap.2020.105959

11. SAE International. (2014). SAE J3016: taxonomy and definitions for terms related to on-road motor vehicle automated driving systems.

12. National Science and Technology Council. (2020). United States Department of Transportation, ensuring american leadership in automated vehicle technologies, automated vehicles 4.0, 2020. https://www.transportation.gov/av/4.

13. National Highway Traffic Safety Administration. (2013). Preliminary Statement of Policy Concerning Automated Vehicles.

14. Smith, B.W. (2013). Summary of levels of driving automation for on-road vehicles. https://cyberlaw.stanford.edu/files/blogi mages/LevelsofDrivingAutomation.pdf. Accessed on 5 Oct 2021.

15. CARTRE CAD. (2018). Connectivity for automated driving (pp. 1-2). https://connectedautomateddriving.eu/wp-content/ uploads/2018/04/CARTRE_Connectivity_Position_Paper.pdf.

16. Cambridge Consultants. (2019). AI in the driving seat: key challenges for the future of advanced driver assistance systems (ADAS). https://www.cambridgeconsultants.com/sites/default/ files/uploaded-pdfs/AIinthedrivingseat-CambridgeConsultants. pdf.

17. Stayton, E., \& Stilgoe, J. (2020). It's time to rethink levels of automation for self-driving vehicles. IEEE Technology \& Society Magazine.

18. Seppelt, B., Reimer, B., Russo, L., Mehler, B., Fisher, J., \& Friedman, D. (2020). Consumer confusion with levels of vehicle automation. In Proceedings of the Tenth International Driving Symposium on Human Factors in Driver Assessment, Training and Vehicle Design (pp. 391-397).

19. Templeton, B. (2016). A critique of NHTSA and SAE "Levels" of self-driving. https://www.templetons.com/brad/roboc ars/levels.html. Accessed on 5 Oct 2021.

20. Bell, S. (2017). The connected car taxonomy decoded: an overview of connected autonomous vehicles \& intelligent transportation systems. Heavy Reading. https://tu-auto.com/files/2018/ 07/HR-Connected-Car-WP-7-10-17.pdf.

21. Synopsis. (2021). The 6 levels of vehicle autonomy explained. https://www.synopsys.com/automotive/autonomous-drivinglevels.html. Accessed on 5 Oct 2021.

22. Baidu. (2020). How coronavirus is accelerating a future with autonomous vehicles. https://www.technologyreview.com/ 2020/05/18/1001760/how-coronavirus-is-accelerating-auton omous-vehicles/. Accessed on 5 Oct 2021.

23. Associated Press. (2020). US agency posts online map to track autonomous vehicle tests. https://www.usnews.com/news/us/ articles/2020-09-02/us-agency-posts-online-map-to-trackautonomous-vehicle-tests. Accessed on 5 Oct 2021.

24. Fee, G. (2020). Preparing for autonomous vehicles, Asphalt Magazine. http://asphaltmagazine.com/autonomous-vehicles/. Accessed on 5 Oct 2021.

25. Andersson, P., \& Ivehammar, P. (2019). Benefits and costs of autonomous trucks and cars. Journal of Transportation Technologies, 09, 121-145. https://doi.org/10.4236/jtts.2019.92008

26. Linder, C. (2020). Self driving freight trucks-Autonomous trucks, Popular Mechanics. https://www.popularmechanics. com/technology/infrastructure/a30196644/self-driving-truckcross-country/. Accessed on 5 Oct 2021.

27. Wanek-Libman, M. (2020). CTDOT scheduled to deploy first full-size automated transit bus in North America, Mass Transit. https://www.masstransitmag.com/alt-mobility/autonomousvehicles/article/21143509/ctdot-scheduled-to-deploy-first-fulls ize-automated-transit-bus-in-north-america. Accessed on 5 Oct 2021. 
28. Future Agenda. (2020). The future of autonomous vehicles: global insights gained from multiple expert discussions. https:// trid.trb.org/view/1722481.

29. Litman, T. (2020). Autonomous vehicle implementation predictions: implications for transport. Planning. https://doi.org/10. 1613/jair.301

30. Lim, H. S. M., \& Taeihagh, A. (2018). Autonomous vehicles for smart and sustainable cities: An in-depth exploration of privacy and cybersecurity implications. Energies. https://doi.org/10. 3390/en 11051062

31. Taeihagh, A., \& Lim, H. S. M. (2018). Governing autonomous vehicles: emerging responses for safety, liability, privacy, cybersecurity, and industry risks. Transport Reviews, 39, 103-128.

32. European Commission. (2018). Autonomous vehicles \& traffic safety. https://ec.europa.eu/transport/road_safety/sites/roads afety/files/pdf/ersosynthesis2018-autonomoussafety.pdf.

33. Zöllner, J., \& Thomas, S. (2015). Autonomous driving. IT Inf Technol, 57, 213-214. https://doi.org/10.1515/itit-2015-0027

34. Adanu, E. K., \& Jones, S. (2017). Effects of human-centered factors on crash injury severities. Journal of Advanced Transportation. https://doi.org/10.1155/2017/1208170

35. Bouchihati, M.E. (2020). The impact of truck platooning on the pavement structure of Dutch motorways: The link between truck platooning and road surface wear. Masters Thesis, Delft University of Technology.

36. Sing, S. (2015). Critical reasons for crashes investigated in the national motor vehicle crash causation survey, Report Number DOT HS 812 506, National Highway Traffic Safety Administration.

37. Fagnant, D. J., \& Kockelman, K. (2015). Preparing a nation for autonomous vehicles: opportunities, barriers and policy recommendations. Transportation Research Part A: Policy and Practice, 77, 167-181. https://doi.org/10.1016/j.tra.2015.04.003

38. Wang, J., Zhang, L., Huang, Y., \& Zhao, J. (2020). Safety of autonomous vehicles. Journal of Advanced Transportation. https://doi.org/10.1155/2020/8867757

39. Faber, T., Sharma, S., Snelder, M., Klunder, G., Tavasszy, L., \& van Lint, H. (2020). Evaluating traffic efficiency and safety by varying truck platoon characteristics in a critical traffic situation. Transportation Research Record: Journal of the Transportation Research Board, 2674, 525-547. https://doi.org/10.1177/03611 98120935443

40. Simko, D.J. (2016). Increasing road infrastructure capacity through the use of autonomous vehicles. Masters Thesis, Naval Postgraduate School, Monterey, United States. Accessed 1 Jul 2016.

41. Tientrakool, P., Ho, Y. C., \& Maxemchuk, N. F. (2011). Highway capacity benefits from using vehicle-to-vehicle communication and sensors for collision avoidance. IEEE Vehicular Technology Society. https://doi.org/10.1109/VETECF.2011.6093130

42. Hoogendoorn, R., Van Arem, B., \& Hoogendoorn, S. (2014). Automated driving, traffic flow efficiency, and human factors. Transportation Research Record, 2422, 113-120. https://doi.org/ 10.3141/2422-13

43. Milakis, D., Van Arem, B., \& Van Wee, B. (2017). Policy and society related implications of automated driving: A review of literature and directions for future research. Journal of Intelligent Transportation Systems: Technology, Planning, and Operations., 21, 324-348. https://doi.org/10.1080/15472450.2017.1291351

44. Shladover, S. E., Su, D., \& Lu, X. Y. (2012). Impacts of cooperative adaptive cruise control on freeway traffic flow. Transportation Research Record, 2324, 63-70. https://doi.org/10.3141/ 2324-08

45. Heaslip, K., Goodall, N., Kim, B., \& Abi Aad, M. (2020). Assessment of Capacity Changes Due to Automated Vehicles on Interstate Corridors. Report Number VTRC 21-R1. Virginia
Department of Transportation \& Federal Highway Administration. http://www.virginiadot.org/vtrc/main/online_reports/pdf/ 21-r1.pdf.

46. Calvert, S. C., Schakel, W. J., \& van Lint, J. W. C. (2017). Will automated vehicles negatively impact traffic flow? Journal of Advanced Transportation. https://doi.org/10.1155/2017/3082781

47. Pakusch, C., Stevens, G., Boden, A., \& Bossauer, P. (2018). Unintended effects of autonomous driving: a study on mobility preferences in the future. Sustain., 10, 1-22. https://doi.org/10. 3390/su10072404

48. Narayanan, S., Chaniotakis, E., \& Antoniou, C. (2020). Shared autonomous vehicle services: A comprehensive review. Transportation Research Part C: Emerging Technologies, 111, 255293. https://doi.org/10.1016/j.trc.2019.12.008

49. Thomas, M., \& Deepti, T. (2018). Reinventing carsharing as a modern (and profitable) service. In The Intelligent Transportation Society of America, Annual Meeting White Paper. https:// ridecell.com/wp-content/uploads/White-Paper-Presentation Reinventing-Carsharing-As-A-Modern-And-Profitable-Servi ce.pdf.

50. Gurumurthy, K. M., \& Kockelman, K. M. (2020). Modeling Americans' autonomous vehicle preferences: A focus on dynamic ride-sharing, privacy \& long-distance mode choices. Technological Forecasting and Social Change., 150, 119792. https://doi.org/10.1016/j.techfore.2019.119792

51. Meyer, G., \& Beiker, S. (2019). Road Vehicle Automation, vol. 5. Springer International Publishing. https://doi.org/10.1007/9783-319-94896-6 12.

52. Bennett, R., Vijaygopal, R., \& Kottasz, R. (2019). Attitudes towards autonomous vehicles among people with physical disabilities. Transportation Research Part A: Policy and Practice, 127, 1-17. https://doi.org/10.1016/j.tra.2019.07.002

53. Kopelias, P., Demiridi, E., Vogiatzis, K., Skabardonis, A., \& Zafiropoulou, V. (2020). Connected \& autonomous vehiclesEnvironmental impacts-A review. Science of the Total Environment, 712, 135237. https://doi.org/10.1016/j.scitotenv.2019. 135237

54. Stern, R. E., Chen, Y., Churchill, M., Wu, F., Delle Monache, M. L., Piccoli, B., Seibold, B., Sprinkle, J., \& Work, D. B. (2019). Quantifying air quality benefits resulting from few autonomous vehicles stabilizing traffic. Transportation Research Part D: Transport and Environment, 67, 351-365. https://doi.org/10. 1016/j.trd.2018.12.008

55. Liu, F., Zhao, F., Liu, Z., \& Hao, H. (2019). Can autonomous vehicle reduce greenhouse gas emissions? A country-level evaluation, Energy Policy., 132, 462-473. https://doi.org/10.1016/j. enpol.2019.06.013

56. Patella, S. M., Aletta, F., \& Mannini, L. (2019). Assessing the impact of autonomous vehicles on urban noise pollution. Noise Mapping, 6, 72-82. https://doi.org/10.1515/noise-2019-0006

57. Winston, C., \& Karpilow, Q. (2020). Autonomous vehicles The road to economic growth. Brookings Institution Press

58. Engholm, A., Pernestål, A., \& Kristoffersson, I. (2020). Cost analysis of driverless truck operations. Transportation Research Record, 2674, 511-524. https://doi.org/10.1177/0361198120 930228

59. Zhang, L., Chen, F., Ma, X., \& Pan, X. (2020). Fuel economy in truck platooning: A literature overview and directions for future research. Journal of Advanced Transportation. https://doi.org/ $10.1155 / 2020 / 2604012$

60. Gungor, O. E., She, R., Al-Qadi, I. L., \& Ouyang, Y. (2020). One for all: Decentralized optimization of lateral position of autonomous trucks in a platoon to improve roadway infrastructure sustainability. Transportation Research Part C: Emerging Technologies, 120, 102783. https://doi.org/10.1016/j.trc.2020. 102783 
61. Gungor, O. E., \& Al-Qadi, I. L. (2020). All for one: centralized optimization of truck platoons to improve roadway infrastructure sustainability. Transportation Research Part C: Emerging Technologies, 114, 84-98. https://doi.org/10.1016/j.trc.2020. 02.002

62. WEVOLVER. (2020). Autonomous Vehicle Technology Report. https://www.wevolver.com/article/2020.autonomous.vehicle. technology.report. Accessed on 5 Oct 2021.

63. Skarbek-Zabkin, A., \& Szczepanek, M. (2018). Autonomous vehicles and their impact on road infrastructure and user safety. In 2018 XI International Science-Technical Conference Automotive Safety (pp. 1-4). IEEE. https://doi.org/10.1109/AUTOSAFE. 2018.8373343.

64. Samak, C.V., Samak, T.V., \& Kandhasamy, S. (2020). Control strategies for autonomous vehicles. http://arxiv.org/abs/2011. 08729 .

65. Vargas, J., Alsweiss, S., Toker, O., Razdan, R., \& Santos, J. (2021). An overview of autonomous vehicles sensors and their vulnerability to weather conditions. Sensors., 21, 1-22. https:// doi.org/10.3390/s21165397

66. Liu, Y., Wang, W., Hua, X., \& Wang, S. (2020). Safety analysis of a modified cooperative adaptive cruise control algorithm accounting for communication delay. Sustainability. https://doi. org $/ 10.3390 /$ su 12187568

67. Filho, C. M., Wolf, D. F., Grassi, V., \& Osorio, F. S. (2014). Longitudinal and lateral control for autonomous ground vehicles. IEEE Intelligent Vehicles Symposium Proceedings. https://doi. org/10.1109/IVS.2014.6856431

68. Mahdinia, I., Arvin, R., Khattak, A. J., \& Ghiasi, A. (2020). Safety, energy, and emissions impacts of adaptive cruise control and cooperative adaptive cruise control. Transportation Research Record, 2674, 253-267. https://doi.org/10.1177/0361198120 918572

69. Hexagon. (2020). Automotive: Driving towards autonomy. https://novatel.com/industries/autonomous-vehicles. Accessed on 5 Oct 2021.

70. . Dominguez, S., Ali, A., Garcia, G., Martinet, P. (2016). Comparison of lateral controllers for autonomous vehicle: experimental results. In IEEE Conf. Intell. Transp. Syst. Proceedings, ITSC, (pp. 1418-1423). https://doi.org/10.1109/ITSC.2016.7795743.

71. Norouzi, A., Masoumi, M., Barari, A., \& Farrokhpour Sani, S. (2019). Lateral control of an autonomous vehicle using integrated backstepping and sliding mode controller. Proceedings of the Institution of Mechanical Engineers, Part K: Journal of Multi-body Dynamics, 233, 141-151. https://doi.org/10.1177/ 1464419318797051

72. Neumeister, D., \& Pape, D. (2019). Automated Vehicles and Adverse Weather: Final Report. Report Number FHWA$J P O-19-755$. Federal Highway Administration.

73. Yoneda, K., Suganuma, N., Yanase, R., \& Aldibaja, M. (2019). Automated driving recognition technologies for adverse weather conditions. International Association of Traffic and Safety Sciences, 43, 253-262.

74. Joubert, N., Reid, T. G. R., \& Noble, F. (2020). Developments in modern GNSS and its impact on autonomous vehicle architectures. IEEE Intelligent Vehicles Symposium Proceedings. https:// doi.org/10.1109/IV47402.2020.9304840

75. Dhall, A., Dai, D., \& Van Gool, L. (2019). Real-time 3D traffic cone detection for autonomous driving. IEEE Intelligent Vehicles Symposium Proceedings. https://doi.org/10.1109/IVS.2019. 8814089

76. Texas Instruments Inc. (2020). Paving the way to self-driving cars with advanced driver assistance systems. https://www. ti.com/lit/wp/sszy019a/sszy019a.pdf?ts=1633481750530\& ref_url=https $\% 253 \mathrm{~A} \% 252 \mathrm{~F} \% 252 \mathrm{Fwww}$.google.com $\% 252 \mathrm{~F}$. Accessed on 5 Oct 2021.
77. Farah, H. (2016). State of Art on Infrastructure for Automated Vehicles: Research Report Summarizing the Scientific Knowledge, Research Projects, Test Sites, Initiatives, and Knowledge Gaps Regarding Infrastructure for Automated Vehicles. Delft University of Technology. https://repository.tudelft.nl/islandora/ object/uuid\%3A27b22b96-159b-4c45-bcca-b0fefc9969be.

78. Poe, C.M. (2020). Connected Roadway Classification System Development. Report number NCHRP 20-24(112). American Association of State Highway and Transportation Officials.

79. European Technology Platform (ERTRAC). (2019). Connected Automated Driving Roadmap Status: Final for Publication. https://connectedautomateddriving.eu/wp-content/uploads/2019/ 04/ERTRAC-CAD-Roadmap-03.04.2019-1.pdf?fbclid=IwAR3 ynV7OpUc07zO3Y1PqQKe4S5xgY_sW8kMbnocwTZ7S7 8Cfz8upjPKRKpo.

80. Boateng, R., Park, H., Smith, B.L., \& Zhang, X. (2019). Providing Traffic Control Device Information in a Connected and Automated Vehicle Environment. Report number VTRC 19-R19. Virginia Department of Transportation. http://www.virginiadot. org/vtrc/main/online_reports/pdf/19-r19.pdf.

81. Garcia, A., \& Camacho-Torregrosa, F. J. (2020). Influence of lane width on semi-autonomous vehicle performance. Transportation Research Record, 2674, 279-286. https://doi.org/10.1177/03611 98120928351

82. Liu, Y., Tight, M., Sun, Q., \& Kang, R. (2019). A systematic review: road infrastructure requirement for connected and autonomous vehicles (CAVs). Journal of Physics: Conference Series. https://doi.org/10.1088/1742-6596/1187/4/042073

83. Washburn, S.S., \& Washburn, L.D. (2018). Future highwaysautomated vehicles: A SunCam online continuing education course. https://s3.amazonaws.com/suncam/docs/208.pdf. Assessed on 5 Oct 2021.

84. National Academy of Sciences. (2015). Towards road transport automation: Opportunities in Public-private collaboration, Summary of the Third EU-US Transportation Research Symposium. In Transportation Research Board Conference Proceedings (No. 52). https://doi.org/10.17226/22087.

85. Binshuang, Z., Jiaying, C., Runmin, Z., \& Xiaoming, H. (2019). Skid resistance demands of asphalt pavement during the braking process of autonomous vehicles. MATEC Web of Conferences, 275, 04002. https://doi.org/10.1051/matecconf/201927504002

86. Hancock, M. W., \& Wright, B. (2018). A policy on geometric design of highways and streets. American Association of State Highway and Transportation Officials. https://doi.org/10.1016/ b978-1-85617-198-4.50009-6

87. Urmson, C. (2006). Driving beyond stopping distance constraints. IEEE International Conference on Intelligent Robots and Systems. https://doi.org/10.1109/IROS.2006.281852

88. Khoury, J., Amine, K., \& Saad, R. A. (2019). An initial investigation of the effects of a fully automated vehicle fleet on geometric design. Journal of Advanced Transportation. https://doi.org/10. $1155 / 2019 / 6126408$

89. Browne, C., Soo, V.K. (2020). Autonomous braking: a comparative study of human, hybrid and autonomous braking control for cars. https://users.cecs.anu.edu.au/ u3951377/student_work/ example_work/15_2226_lp_jamesl.pdf. Assessed on 5 Oct 2021.

90. Velodyne LiDAR Inc. (2019). User's Manual and Programming Guide: High Definition LiDAR Sensors. https://www.manualslib. com/manual/1988532/Velodyne-Hdl-64e-S3.html. Assessed on 5 Oct 2021.

91. Welde, Y., \& Qiao, F. (2020). Effects of autonomous and automated vehicles on stopping sight distance and vertical curves in geometric design. Resilience and Sustainable Transportation Systems, 3, 148-156.

92. Wang, S. \& Yu, B. (2019). Impacts on the Geometric Design of Highway from Non Autonomous To Autonomous Vehicles (L1 
L4). In Transp. Res. Board 98th Annu. Meet (pp. 1-6). Washington, DC. https://trid.trb.org/view/1759147.

93. Buiter, R., Cortenraad, W.M.H., \& van Eck, A.C., van Rij, H. (1989). Effects of transverse distribution of heavy vehicles on thickness design of full-depth asphalt pavements. Transportation Research Record, 66-74.

94. Blab, R., \& Litzka, J. (1995). Measurements of the lateral distribution of heavy vehicles and its effects on the design of road pavements. In Proc. Int. Symp. Heavy Veh. Weight. Dimens. (pp. 389-395).

95. Gungor, O. E., \& Al-Qadi, I. L. (2020). Wander 2D: A flexible pavement design framework for autonomous and connected trucks. International Journal of Pavement Engineering, . https:// doi.org/10.1080/10298436.2020.1735636

96. Siddharthan, R. V., Nasimifar, M., Tan, X., \& Hajj, E. Y. (2017). Investigation of impact of wheel wander on pavement performance. Road Materials and Pavement Design, 18, 390-407. https://doi.org/10.1080/14680629.2016.1162730

97. ARA Inc. (2004). Guide for Mechanistic-Empirical Design of New and Rehabilitated Pavement Structures. Transportation Research Board. http://library1.nida.ac.th/termpaper6/sd/2554/ 19755.pdf.

98. Erlingsson, S. (2012). Rutting development in a flexible pavement structure. Road Materials and Pavement Design, 13, 218234. https://doi.org/10.1080/14680629.2012.682383

99. Wu, R., \& Harvey, J.T. (2008). Evaluation of the Effect of Wander on Rutting Performance in HVS Tests Evaluation of the Effect of Wander on Rutting Performance in HVS Tests. In Third Int. Conf. Accel. Pavement Test. Oct. 2008. Madrid.

100. Gungor, O.E. (2018). Final report: a literature review on wheel wander. Illinois Asphalt Pavement Association. https://il-aspha lt.org/files/2915/1743/1516/Erman_Gungor_2017_UIUC.pdf.

101. Lee, J.-W. (2012). Model based predictive control for automated lane centering/changing control systems. U.S. Patent No. $8,190,330$. Washington, DC: U.S. Patent and Trademark Office.

102. Noorvand, H., Karnati, G., \& Underwood, B. S. (2017). Autonomous vehicles: assessment of the implications of truck positioning on flexible pavement performance and design. Transportation Research Record, 2640, 21-28. https://doi.org/10.3141/2640-03

103. Zhou, F., Hu, S., Chrysler, S. T., Kim, Y., Damnjanovic, I., Talebpour, A., \& Espejo, A. (2019). Optimization of lateral wandering of automated vehicles to reduce hydroplaning potential and to improve pavement life. Transportation Research Record. https:// doi.org/10.1177/0361198119853560

104. Said, S. F., Hakim, H., Oscarsson, E., \& Hjort, M. (2011). Prediction of flow rutting in asphalt concrete layers. International Journal of Pavement Engineering, 12, 519-532. https://doi.org/ 10.1080/10298436.2011.559549

105. Said, S. F., Hakim, H., \& Eriksson, O. (2013). Rheological characterization of asphalt concrete using a shear box. Journal of Testing and Evaluation, 41, 602-610. https://doi.org/10.1520/ JTE20120177

106. Jelagin, D., Ahmed, A., Lu, X., \& Said, S. (2018). Asphalt Layer Rutting Performance Prediction Tools. Report Number VTI rapport 968A. Swedish National Road and Transport Research Institute.

107. Almeida, A., Moreira, J. J. M., Silva, J. P., \& Viteri, C. G. V. (2021). Impact of traffic loads on flexible pavements considering Ecuador's traffic and pavement condition. International Journal of Pavement Engineering, 22, 700-707. https://doi.org/10.1080/ 10298436.2019.1640362

108. Pais, J. C., Figueiras, H., Pereira, P., \& Kaloush, K. (2019). The pavements cost due to traffic overloads. International Journal of Pavement Engineering, 20, 1463-1473. https://doi.org/10.1080/ 10298436.2018.1435876
109. Shafiee, M.H., Nassiri, S., \& Bayat, A. (2014). Field investigation of the effect of operational speed and lateral wheel wander on flexible pavement mechanistic responses. In 2014 Transp. Assoc. Canada Conf. Exhib. Past, Present. Futur. ATC 2014.

110. Said, S., \& Hakim, H. (2012). Influence of traffic variables on rut formation in asphalt concrete layers. In HVTT12 12th Int. Symp. Heavy Veh. Transp. Technol. (pp. 1-13).

111. Chen, F., Song, M., Ma, X., \& Zhu, X. (2019). Assess the impacts of different autonomous trucks' lateral control modes on asphalt pavement performance. Transportation Research Part C: Emerging Technologies, 103, 17-29. https://doi.org/10.1016/j. trc.2019.04.001

112. Rana, M. (2020). Effects of autonomous vehicles on pavement distress \& road safety and pavement distress optimization. Master's Thesis, Memorial University of Newfoundland.

113. Rana, M. M., \& Hossain, K. (2021). Impact of autonomous truck implementation: rutting and highway safety perspectives. Road Materials and Pavement Design. https://doi.org/10.1080/14680 629.2021.1963815

114. Ahmed, M., \& Yang, G. (2019). Impacts of cooperative automated transportation on wyoming highway infrastructure. University of Wyoming. https://www.dot.state.wy.us/files/live/sites/ wydot/files/shared/Planning/Research/Completed\%20Projects\% 20for $\% 202009 /$ RS0 $2220 \% 20$ Impacts\%20of\%20CAT\%20on\% 20Wyoming\%20Infrastructure.pdf.

115. Rana, M. M., \& Hossain, K. (2021). Simulation of autonomous truck for minimizing asphalt pavement distresses. Road Materials and Pavement Design. https://doi.org/10.1080/14680629. 2021.1883469

116. Chen, F., Song, M., \& Ma, X. (2020). A lateral control scheme of autonomous vehicles considering pavement sustainability. Journal of Cleaner Production, 256, 120669. https://doi.org/10. 1016/j.jclepro.2020.120669

117. Marsac, P., Blanc, J., Chupin, O., Gabet, T., Hammoum, F., Garg, N., \& Nguyen, M.L. (2020). Optimization of truck platoon wander patterns based on thermo-viscoelastic simulations to mitigate the damage effects on road structures. In Proc. 6th APT Conf.a

118. Song, M., Chen, F., \& Ma, X. (2021). Organization of autonomous truck platoon considering energy saving and pavement fatigue. Transportation Research Part D: Transport and Environment, 90, 102667. https://doi.org/10.1016/j.trd.2020.102667

119. Savio, D., Nivitha, M. R., \& Krishnan, J. M. (2019). Influence of climate and traffic on the HMA rut-depth for India. International Journal of Pavement Research and Technology, 12, 595-603.

120. Jia, Y., Wang, S., Peng, J., Gao, Y., Hu, D., Zhao, X. (2020). Evaluation of pavement rutting based on driving safety of vehicles. International Journal of Pavement Research and Technology, 1-13.

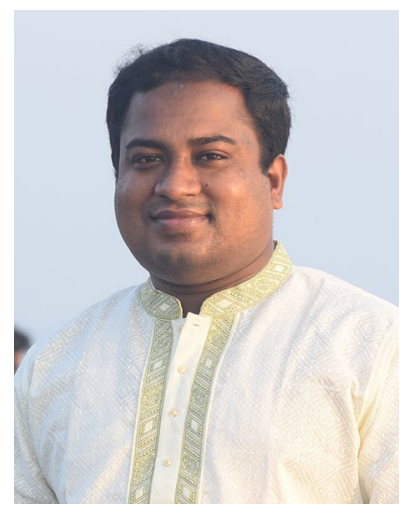

Md. Masud Rana has recently completed M.Eng. in Pavement Engineering at the Department of Civil Engineering of Memorial University of Newfoundland, Canada. Prior to that, Mr. Rana finished his undergraduate (B.Sc in Civil Engineering) in Rajshahi University of Engineering \& Technology (RUET), Bangladesh and joined as faculty member in RUET for undergraduate study. After completion of his M.Eng., now he is continuing his service as faculty member in RUET. Mr. Rana's research 
includes the effect of autonomous vehicles and climate change on the performance of asphalt pavement.

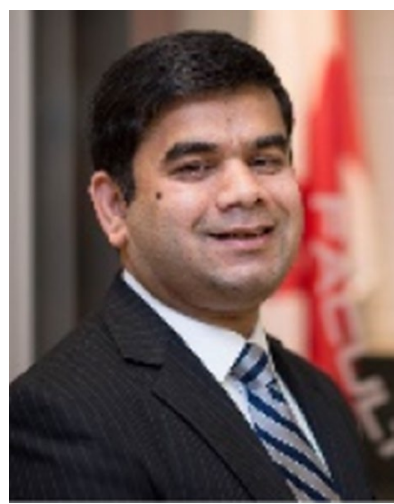

Kamal Hossain is an Assistant Professor of Pavement Engineering at the Department of Civil and Environmental Engineering of Carleton University in Ottawa, Canada. Previously, Dr. Hossain served as a faculty member at the Department of Civil Engineering of Memorial University of Newfoundland in Canada. Prior to that, Dr. Hossain was a postdoctoral researcher in pavement and transportation research groups at the Illinois Center for Transportation of University of Illinois at Urbana-Champaign in USA, and at CPATT and ITSS Lab of University of Waterloo in Canada. Dr. Hossain earned his $\mathrm{PhD}$ in Transportation Engineering from University of Waterloo. Dr. Hossain a member of the Standing Committees on Pavement Maintenance (AKT30) and Asphalt Binder (AKM20) at the United Sates Transportation Research Board (TRB). 